\title{
७MONÇÕES

\section{O AGROLOBBY EM MÚLTIPLAS ESCALAS: Uma Análise da Influência do Agronegócio na Política Externa Brasileira}

\author{
THE MULTIPLE SCALE OF AGRO LOBBY: An Analysis of the Influence of \\ Agribusiness on Brazilian Foreign Policy
}

AGRO LOBBY EN MÚLTIPLES ESCALAS: Un análisis de la influencia de la agroindustria en la política exterior brasileña

\author{
AMANDA JANDREY SIEBENEICHLER \\ Doutoranda e Mestre em Estudos Estratégicos Internacionais pela \\ Universidade Federal do Rio Grande do Sul (UFRGS), \\ Porto Alegre- Rio Grande do Sul, Brasil. \\ amandajsiebeneichler@gmail.com \\ ORCID: https://orcid.org/0000-0001-8373-6459
}

\begin{abstract}
Resumo: O lobby do agronegócio é um importante meio pelo qual a influência de grupos corporativos do mercado agroalimentar mundial penetra em espaços públicos de tomada de decisão e influência seus resultados, especialmente quando muitos desses lobistas atuam diretamente em instituições governamentais e, de modo geral, influenciam sobre decisões quanto à aprovação de pesticidas, sementes transgênicas, acordos comerciais ou agendas nacionais ou internacionais de pesquisa. Pensando nisso, o objetivo deste artigo é analisar o peso do lobby do agronegócio na esfera doméstica no processo de tomada de decisão da política externa. Fazendo uso da noção de foreign policy system approach e do modelo dos Jogos de Dois Níveis, podese perceber uma escalada da participação da Frente Parlamentar da Agropecuária e do lobby privado que acompanha o desenvolvimento da política externa do Brasil no período de 2010 a 2020. A representação desse grupo, por meio de sua atuação no Congresso, abre canais de diálogos que permitem que as demandas específicas desse grupo ganhem visibilidade, garantindo espaços de atuação em matérias econômicas, sociais, ambientais e políticas.
\end{abstract}

Palavras-Chave: Agronegócio; Política Externa Brasileira; FPA. 
Abstract: The agribusiness lobby is an important group by which the influence of corporate actors in the global agri-food market penetrates public spaces for decision-making and influences their results, especially when many of these lobbyists work directly in government institutions and, in general, influence decisions regarding the approval of pesticides, transgenic seeds, commercial agreements or national or international research agendas. The main objective of this research is to analyze the weight of the agribusiness lobby in the domestic sphere of the foreign policy decision-making process. Using the notion of foreign policy system approach and the Logic of Two-Level Games, one can see an increase in the participation of the Parliamentary Agricultural Front and the private lobby that accompanies it in the development of foreign policy from 2010 to 2020. The representation of this group present in Congress, opens channels of dialogues that allow the specific demands of this group to gain visibility, as well as the endorsement of their opinions on the most diverse subjects.

Keywords: Agribusiness; Brazilian Foreign Policy; PFA.

Resumen: El lobby agroindustrial es un medio importante por el cual la influencia de los grupos corporativos en el mercado agroalimentario global penetra en los espacios públicos para la toma de decisiones e influye en sus resultados, especialmente cuando muchos de estos lobbistas trabajan directamente en instituciones gubernamentales $y$, en general, influyen sobre decisiones relativas a la aprobación de plaguicidas, semillas transgénicas, acuerdos comerciales o agendas de investigación nacionales o internacionales. Teniendo esto en cuenta, el propósito de este artículo es analizar el peso del lobby agroindustrial en el ámbito interno en el proceso de toma de decisiones de política exterior. Usando la noción de enfoque de sistema de política exterior y el modelo de Juegos de Dos Niveles, se puede ver un aumento en la participación del Frente Parlamentario Agropecuario y el lobby privado que acompaña el desarrollo de la política exterior de Brasil en el período de 2010 a 2020. La representación de este grupo, a través de su actuación en el Congreso, abre canales de diálogo que permiten visibilizar las demandas específicas de este grupo, garantizando espacios de acción en materia económica, social, ambiental y política.

Palabras-Clave: Agroindustria; Política exterior brasileña; FPA. 


\section{INTRODUÇÃO}

A recuperação da confiança nos investimentos e na expansão do comércio internacional a partir da década de 1970 adveio, em parte do avanço da tecnologia, em parte da atuação de Estados nacionais considerado importantes no sistema internacional - como Estados Unidos, Japão e países da Europa - ao levarem a ideia de uma democracia capitalista ao resto do mundo. Isso provocou uma expansão da globalização, gerando o que autores como Adda (1997), Chalout e Brunelle (1998) e Benko (2002) chamam de mundialização ${ }^{1}$ da produção e uma transnacionalização da economia em tal ponto, que acaba causando o que lanni (1997) chama de uma crise de governabilidade ao reduzir a capacidade decisória dos Estados quando se considera que esse processo de globalização corresponde a ações que transcendem nações e regiões.

Esse processo deu margem para que o âmbito público de tomada de decisão desse espaço para que empresas transnacionais exercessem uma espécie de domínio sobre o mercado agroalimentar mundial e, inclusive, sobre a formulação de políticas, provocando o desmantelamento do poder estatal, estabelecendo padrões de produção e consumo, relativizando o processo produtivo atual e fortalecendo um discurso que rotula a fome e as crises causadas por ela como um "problema de ordem quantitativa (uma deficiência de produtividade)", ignorando a possibilidade de que isso possa ser um reflexo de um regime agroalimentar capitalista (SANTOS, 2017, p. 296).

O lobby do agronegócio, institucionalizado no Brasil por meio da Frente Parlamentar da Agropecuária (FPA), por meio do Ato da Mesa Diretora $n^{\circ}$ 69, em 2005, e sustentado a partir do financiamento de grupos como o Instituto Pensar Agro (IPA), a Associação de Produtores de Soja no Brasil (Aprosoja) e a Associação Brasileira de Produtores de Milho (ABRAMILHO), é um meio pelo qual a influência de grupos corporativos do mercado agroalimentar mundial penetra espaços públicos de tomada de decisão e interfere nestes

\footnotetext{
${ }^{1}$ Conforme destaca Jacques Adda (1997), citar a mundialização evoca a dominação de um espaço econômico, o capitalismo sobre o espaço mundial. Autores como Chaloult e Brunelle (1998) caracterizam mundialização como um sinônimo de globalização. Benko (2002, p. 45) designa mundialização como a crescente integração, também chamada de globalização financeira, integração de mercados decorrente de políticas de liberalização e de novas tecnologias, que permitem a intensificação de fluxos de investimento e de capital em escala planetária.
} 
espaços decisórios, conforme demonstra o estudo de McKeon (2009). Pode-se observar sua presença em espaços públicos a partir da composição da FPA, cujos membros como Blairo Maggi e Luiz Nishimori, são grandes representantes do agronegócio no Congresso, donos de empresas conectadas ao setor (AUDI; ESSI, 2018).

Isto posto, o objetivo deste trabalho consiste na análise do peso do lobby do agronegócio no processo de formulação de política externa brasileira por meio do comportamento da FPA. Nesse sentido, considera-se a hipótese de que há uma convergência entre os interesses da FPA para com o lobby, tornando-os um Grupo de Interesse que atua através de instrumentos institucionalizados, chamados por Boarin e Resende (2018, p. 217), de "ex ante e ex post na produção de política externa". A unificação destes atores em um grupo de interesse, garante o que Ribeiro (2016) chama de um "peso duplo" quanto à formulação de política externa brasileira, levando a decisões que atendem a interesses específicos do setor agroexportador.

Como explica Figueira (2011), é importante compreender de que maneira a política externa é feita e qual o caminho que ela percorre, tornando-se primordial a definição do nível de análise, verificando que a unidade decisória pode ser considerada unitária ou desagregada à medida que apresenta conflitos inerentes decorrente da variedade de atores ou se é uma estrutura homogênea A proposta de Figueira (2011) vai ao encontro do que sugerem Sólomon e Pinheiro (2013), que, ao tratarem da política externa como uma política pública, ressaltam a necessidade de se considerar sua elaboração inserida em um processo de barganha, que envolve demandas e conflitos de variados grupos domésticos, verificando sua agregação em um contexto de "luta política". O termo "luta política" foi trazido por Robert Putnam (2010) ao explorar uma relação "interméstica" da política externa, arguindo que uma avaliação adequada dos determinantes domésticos presentes no processo decisório, precisaria considerar partidos, classes sociais, grupos de interesse, legisladores e a opinião pública.

De modo a averiguar a influência do agronegócio na formulação de política externa brasileira (PEB), esta pesquisa sugere três objetivos específicos a serem verificados: a) analisar a composição da FPA e aferir seus interesses; b) apontar a conexão com o capital privado na formação do lobby por meio do Instituto Pensar Agro (IPA), grande financiador do setor; e c) 
apontar a participação na política externa por meio da Comissão de Relações Exteriores e de Defesa Nacional (CREDN) na Câmara de Deputados. Metodologicamente, caracteriza-se como um estudo analítico-descritivo, abordando conceitos teóricos importantes ao entendimento do comportamento do órgão formulador de política externa, Ministério das Relações Exteriores (MRE), e o grupo de interesse.

Emprega, a noção de foreign policy system approach, abordando o conceito de inputs, que seriam ações, contextos ou acontecimentos que visam determinar e/ou influenciar decisões políticas a partir da atuação sobre policy makers, e outputs, caracterizando-se por ações consolidadas após a interação com a dinâmica decisória. Destacam-se, portanto, duas unidades de análise: o MRE, espaço formulador de política externa, sujeito a interferência de outros atores, e o grupo de interesse, caracterizado aqui como a união do lobby e da FPA. O método aplicado ao desenvolvimento desta pesquisa decorre de uma abordagem dedutiva, partindo de uma abordagem mais geral da política externa, embasada pelo modelo dos Jogos de Dois Níveis de Robert Putnam (2010), para a atuação de um grupo de interesse específico. Propõe-se avaliar a participação de representantes do agronegócio em matérias de política externa a partir da CREDN, Comissão Permanente da Câmara, e verificar como o grupo atua em questões que impactam sobre o setor. As técnicas de pesquisas adotadas foram pesquisa bibliográfica (artigos, dissertações, teses e livros) e documental (discursos, documentos e relatórios).

A estrutura que pode ser observada neste artigo divide-se em três seções. A primeira seção busca apresentar o foreign policy system de modo a apontar como o instrumento analítico permite a análise da interação entre agrolobby e política externa brasileira. A segunda seção busca apresentar a FPA, seus integrantes e seus interesses, buscando verificar como ocorre a formação de um lobby do agronegócio, caracterizando o grupo de interesse e averiguando sua aproximação com o setor privado por meio do IPA. A terceira seção pretende apontar a atuação do agronegócio na CREDN, indicando como sua presença afeta matérias de política externa, especialmente questões que impactam sobre o setor. 


\section{FOREIGN POLICY SYSTEM COMO ENFOQUE NA ANÁLISE DA INFLUÊNCIA DO AGROLOBBY NA POLÍTICA EXTERNA BRASILEIRA}

Compreender a formulação de PEB por meio de ferramentas de análise que possam abranger a diversidade de atores na nova política externa, é importante para a análise de como esse agrolobby exerce influência em PEB. Mesquita (2014) defende que um bom recurso de análise na compreensão do processo de formulação de PEB seria um sistema complexo de ações, do inglês, foreign policy system. A proposta considera a política externa "como fluxos de ações contínuos e confusos, constituídos pela conjunção de decisões políticas, de inação política, procedimentos burocráticos, padrões cognitivos, e pelo constrangimento do ambiente no qual ela está inserida" (MESQUITA, 2014, p. 73). Ela foi pensada a partir da ideia da existência de inputs e outputs, formando um ciclo, conforme a Figura 1.

Figura 1 - Fluxograma explicativo de foreign policy system

AMBIENTE

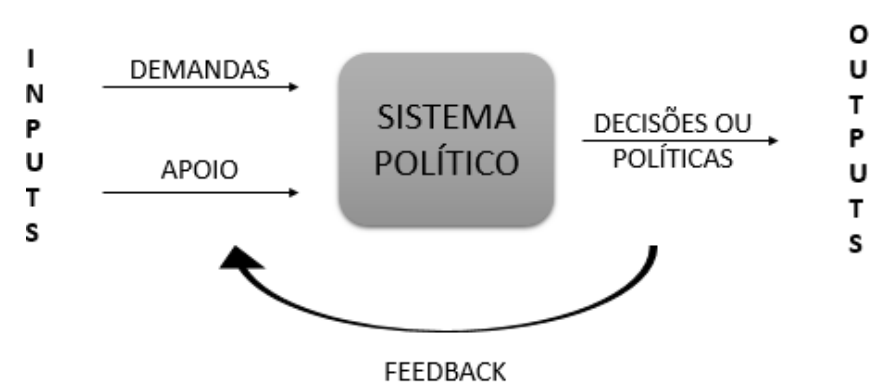

Fonte: Adaptado de Mesquita (2014).

Como explica Figueira (2011), inputs são elementos que exercem influência sobre os resultados, sejam eles grupos de interesse, pressão, a demanda desses grupos e as estruturas de apoio desenvolvidas para suporte de determinadas decisões. No caso dos outputs, são ações ou decisões consolidadas com base nos elementos de influência. Este processo é caracterizado como um ciclo, um espaço onde há um fluxo contínuo de ações, constituído a partir da conjunção de decisões políticas, ou da inação política, de procedimentos 
burocráticos, padrões cognitivos ou pelo constrangimento do ambiente no qual a política se insere (MESQUITA, 2014).

Clarke (2000) delimita cinco passos para a análise, que consistem em identificar as partes, o sistema, o dinamismo neste sistema, a relação com o ambiente no qual se insere e a interação entre as diferentes variáveis que incidem sobre o processo. Assim, as duas unidades de análise propostas para a elaboração deste artigo consistiam no lobby do agronegócio somado à FPA e a unidade formuladora de política externa, o Ministério das Relações Exteriores (MRE), servindo como atores no processo de tomada de decisão. A dinâmica do processo pode ser analisada a partir da complexidade sobre um elemento considerado estático, a formulação de política externa, sendo influenciada por elementos externos, neste caso, a atividade da FPA e do agrolobby. Leva-se em consideração ainda, o ambiente no qual essa política está inserida, variando conforme governo e demandas domésticas e internacionais, além das variáveis que influenciam a PEB.

O conceito de input trazido por Figueira (2011) é trabalhado aqui a partir do contexto das políticas voltadas aos interesses do agronegócio. O processo de intensificação da participação da FPA não é recente. Mesmo durante o governo de Lula da Silva, o processo decisório já visava agradar aos variados influenciadores (VIGEVANI, CEPALUNI, 2007). Suas atividades podem ser observadas no ingresso em espaços públicos, seja por meio da associação com organizações, seja por meio da eleição direta de candidatos.

A "agenda positiva" do agronegócio é um elemento constantemente presente nas pautas das decisões políticas brasileiras. Visto como um setor estratégico, sua relevância é dada a partir de afirmativas como "o agronegócio alimenta o Brasil" ou "o agronegócio sustenta o PIB brasileiro". Tais afirmativas precisam ser analisadas com cautela, especialmente quando, com relação à primeira afirmativa, sabe-se que o agronegócio é responsável pela exportação de commodities, como soja e milho para ração, mas o alimento disponibilizado para a população origina, majoritariamente, de agricultura familiar, conforme demonstra o Censo Agropecuário de 2017 (IBGE, 2017). Quanto à segunda afirmativa, devese levar em consideração a dependência do setor em insumos externos - sementes, agrotóxicos, fertilizantes e máquinas -, fazendo grande parte da receita do agronegócio 
permanecer nas mãos de transnacionais como Bayer-Monsanto, Cargill, Basf, Syngenta, Bunge e Deyfus (SAUER, 2008; SANTARELLI; BURITY, 2017; TYGEL, 2017).

Assim, tem-se os outputs, que seriam as políticas consolidadas a partir da dinâmica de inputs. A atual conjuntura política revela um contínuo desmonte das políticas de proteção social e combate à fome, somadas a medidas como a Emenda Constitucional no 95, que congela gastos sociais em vinte anos, e ao desmonte no setor previdenciário e trabalhista. Evidenciam-se efeitos de austeridade fiscal que afetam de forma distinta diversas camadas da população, especialmente aquelas que mais dependem de serviços públicos e encontram-se em situação de vulnerabilidade (FÓRUM 21 et al., 2016; SANTARELLI; BURITY, 2017). Isso dá margem à ação de atores privados, como coloca Clapp (2014), ao explicar que a financeirização abre portas para as oportunidades de acumulação no sistema agroalimentar global, fazendo com que o crescente número de atores privados e as ferramentas específicas de investimento financeiro baseadas na agricultura, provoquem o que a autora chama de "distanciamento" dentro do sistema agroalimentar. Esse distanciamento se dá por meio da financeirização da agricultura, que contribui para um maior número de atores privados nas cadeias de commodities, resultando na comida como uma forma física de derivativos de commodities agrícolas. Se dá também por meio de lacunas no conhecimento sobre os impactos sociais e ambientais da produção de alimentos, processos que acabam afetando a distribuição de poder e influência sobre esse sistema, desenvolvendo uma governança corporativa (KNEEN, 1995).

Esse distanciamento provoca a ideia de obscuridade quanto ao papel que esses atores privados desempenham, tornando sua relação com consequência sociais e ecológicas mais subjetiva, especialmente quando esses atores fazem uso de derivativos financeiros como uma proeminente forma de investimento no setor de alimentos, ou de participação no setor público. Como explicam Clapp e Fuchs (2009), estes investimentos afetam os preços dos alimentos, uma vez que estes atores privados exercem certo domínio sobre o setor de alimentos, e fornecem capital para que estas empresas realizem investimentos produtivos, o que frequentemente produz resultados negativos, como preços altos e voláteis e problemas ambientais e sociais associados. Essa financeirização garante menor transparência sobre quais 
atores estão envolvidos na condução desse tipo de tendência, evocando discursos que culpabilizam com mais frequência as ações dos Estados e menos a relação destes atores com o domínio do sistema agroalimentar. O distanciamento citado por Clapp (2014), portanto, molda o contexto político dos grupos que procuram se opor a essa financeirização - as dinâmicas de resistência ao processo -, o que dificulta qualquer tentativa de desafiar as normas dominantes que giram em torno da economia e da composição do sistema alimentar mundial

Nesse sentido, tem-se um novo input, onde novas demandas e novos atores influenciam o processo decisório de PEB a partir das transformações observadas no cenário internacional e dos melhores resultados para o lobby do agronegócio. Logo, a utilização de foreign policy system a partir da dinâmica de inputs e outputs cabe a este estudo por permitir relacionar as unidades de análise ao processo político que compõe as relações internacionais do Brasil, garantindo uma avaliação, tanto sobre os atores, quanto sobre as ações realizadas por estes atores

\section{AGRLOBBY COMO UM GRUPO DE INTERESSE E SUA ASSOCIAÇÃO COM A FPA}

Gorender (1997) caracteriza a atual estrutura do mercado agroalimentar por um processo de financeirização, que seria o movimento das economias e das fronteiras políticas dos Estados, sendo ultrapassadas por empresas agindo no cenário mundial, de modo que provocam alterações nas relações de produção e acentuam traços fundamentais do capital e suas dinâmicas. Bjorkhaug, Magnan e Lawrence (2020) definem essa estrutura de financeirização a partir da crescente influência de atores financeiros e lógicas que transformam o sistema agroalimentar. Como explica Epstein (2005), o processo de financeirização da agricultura é representado pela acumulação-regulação do capitalismo, onde o valor das commodities passa a ser definido por atores e instituições financeiras. Tal processo fez com que o alimento se tornasse um ativo financeiro, onde a formação de preços, 
a integração de regiões ao comércio internacional e os sistemas de produção se encontrem vinculados às especulações e aos interesses das elites do mercado agroalimentar mundial (CLAPP, 2016).

Essa dinâmica de transformação dos sistemas de produção e consumo, que ganha mais força a partir da década de 1990, garante três argumentos de análise desse processo, sendo eles: (1) a alteração do sistema de produção a partir da incorporação de novas tecnologias e da ideia de uma produção mais flexível e intensificada; (2) a transnacionalização da atividade produtiva a partir da ideia da perda de nacionalidade de grandes conglomerados empresariais; e (3) a redução do poder dos Estados nacionais diante do aumento do poder do setor privado (CLAPP, 2014).

Conforme sugere lanni (1997), muitas das diretrizes que se conectam aos setores da economia, atendem interesses de corporações transnacionais ou de países cuja imagem é vista por outros países ou instituições no sistema internacional como dominantes, por exercerem influência e poder considerável em determinados setores. Hirst e Thompson (1998) explicam isso a partir da desigualdade de oportunidades de investimentos surgidos por causa da mobilidade de capital, favorecendo, assim, grandes centros de interesses e a construção de poder corporativo cada vez mais sólido no âmbito do mercado agroalimentar global. Conforme explica Santos (2017), é difícil estabelecer um período no qual essas corporações passaram a exercer influência sobre a agenda agroalimentar dos países ou tiveram suas atividades associadas a espaços públicos.

As décadas de 1950 e 1960, período marcado pelo paradigma da Revolução Verde, apresentavam um certo otimismo quanto ao sucesso do modelo do agronegócio norteamericano na luta contra a fome, muito embora fosse um movimento voltado à exportação e atrelado a grandes bancos de crédito agrícola. A Revolução Verde foi um pacote de motomecanização que tinha o objetivo de otimizar a produção de bens alimentares, o que permitiria a superação da fome a partir do aumento na produção de alimentos (COCA, 2019). A exportação desse modelo era chamada de New Agricultural Countries e apresentava 
condições ligadas a políticas neoliberais estabelecidas sobre a agricultura dos países do Sul², legitimando um regime agrolimentar corporativo conduzido pelo agronegócio e assentado em ganhos econômicos.

A abordagem teórico-metodológica de um regime agroalimentar corporativo foi, de modo pioneiro, trabalhado por Harriet Friedman (1987), discutindo a ordem políticoeconômica internacional que se estabeleceu após a Segunda Guerra Mundial. Posteriormente, trabalhos como os de McMichael $(2013,2016)$ trouxeram novos elementos à abordagem dos regimes agroalimentares, como o neoliberalismo, o pós-modernismo e o poder corporativo. Regimes internacionais são definidos por Krasner (2012), como princípios, normas, regras e procedimentos do processo de tomada de decisão em determinadas áreas das relações internacionais às quais se entrelaçam as expectativas e interesses de atores. Conforme Coca (2019), o regime alimentar abastece as relações entre Estado e mercado, associado às ordens político-econômicas institucionalizadas em dois regimes agroalimentares: o Projeto Colonial, que se refere à industrialização britânica e à produção e exportação de bens primários pelas colônias, e ao contexto da Guerra Fria, caracterizado pela hegemonia estadunidense, por um Projeto de Desenvolvimento e pelo dólar como moeda estabilizadora.

Embora não exista concordância com a existência de um terceiro regime agroalimentar (BERNSTEIN, 2016; FRIEDMAN, 2016), para McMichael (2016), há uma nova composição do sistema agroalimentar, onde, a partir do modelo neoliberal sistematizado pelo Consenso de Washington, em 1999, as funções dos Estados são modificadas a tal ponto que estes passam a ser subservientes ao poder corporativo. Observa-se isso a partir da diminuição de tributação para setores da economia, investimento em infraestrutura no que se refere à circulação de bens e capitais e maior financiamento público de atividades produtivas do capital provado, tendo o agronegócio brasileiro como exemplo (MCMICHAEL, 2016; COCA, 2019).

\footnotetext{
${ }^{2}$ As políticas neoliberais da Revolução Verde estabelecidas para os países do sul global incluíam o fim do incentivo público à agricultura familiar em países periféricos, barreiras tarifárias aos alimentos agrícolas norteamericanos e europeus e estímulo à eliminação de políticas nacionais com relação ao estoque de sementes e grãos, favorecendo a inserção de capital estrangeiro na agricultura e favorecendo uma matriz colonial em países antes autossuficientes e exportadores em determinadas culturas, agora importadores e/ou dependentes de ajuda alimentar internacional para a satisfação das necessidades alimentares e nutricionais da população mais pobre (ARAGÃO; SANTOS, 2017).
} 
O agronegócio, definido por Iglécias (2007, p. 76), seria

Toda e qualquer atividade ligada ao comércio de produtos agropecuários.
Entretanto, a acepção que faremos deste termo ao longo do artigo referir-se-á ao
conjunto de atividades agropecuárias relativas à produção, industrialização,
distribuição e comercialização de produtos agropecuários, pautadas por algumas
características bastante peculiares, como competitividade, gestão, foco no
consumidor, altos índices de produtividade, desenvolvimento permanente de
ciência e tecnologia, intensividade em capital (e, em algumas cadeias produtivas,
também em trabalho) e inserção nas cadeias produtivas, financeiras e comerciais
globais.

A palavra agronegócio é uma adaptação do conceito de agribusiness desenvolvida por John Davis e Ray Goldberg, no artigo A concept of agribusiness, publicado em 1957. Sua utilização ganhou força ao longo da década de 1960 e ampliou-se dentro do vocabulário dos países. O conceito estaria relacionado à revolução tecnológica e ao progresso científico da agricultura, exigindo políticas públicas de apoio à exploração agrícola diante do aumento de custos produtivos, de transporte, processamento e de distribuição de alimentos e fibras, como explica Mendonça (2013). Este é um modelo que difere da agricultura familiar, por exemplo, conceito em construção, definido por Carneiro (1999) e Rambo, Tarsitano e Laforga (2016), como uma unidade de produção em que estão intimamente relacionadas a terra, o trabalho e a família, ou seja, ao mesmo tempo em que a família é dona dos meios de produção, ela também representa a força de trabalho.

Pautado nessa definição de agronegócio, o grupo de interesse representado por este lobby aqui trabalhado, constitui-se de atores privados, pela definição de agronegócio proposta por Iglécias (2007), e pela FPA. A título de conceituação, grupo de interesse pode ser definido como uma força social que emerge de um grupo, que se organiza e atua com o objetivo de conquistar vantagens e benefícios conforme sua natureza, podendo estes serem profissionais, econômicos, religiosos ou ligados a qualquer função social (CASTRO; FALCÃO, 2004). Um grupo de interesse exerce pressão sobre o governo, seja no âmbito doméstico, por meio do Congresso Nacional, seja a nível internacional, a partir da representação em eventos ou pressão financeira. A partir da atuação desse grupo de interesse, pode-se compreender como 
a relação entre doméstico e externo estão intrinsecamente ligadas, enfatizando o modelo proposto por Robert Putnam (2010).

Robert Putnam, cientista político, publicou o artigo Diplomacy and Domestic Politics: The Logic of the Two-Level Games, na revista International Organization, em 1988 originalmente, apresentando o modelo dos Jogos de Dois Níveis, onde apontava a necessidade de se transcender a ideia de que havia uma política importante nas relações internacionais, levando-nos a compreender a reciprocidade entre os espaços doméstico e externo. Conforme Putnam (2010), a posição de um país é calculada a partir das pressões exercidas sobre o governo em ambos os níveis, de modo a satisfazer os objetivos do Estado nacional, como coloca Ribeiro (2016, p. 7), "sem criar um conflito com as partes envolvidas". Este modelo é descrito da seguinte maneira:

\footnotetext{
Do outro lado do tabuleiro internacional sentam as contrapartes estrangeiras, ao lado das quais sentam diplomatas e outros assessores internacionais. Em volta do tabuleiro doméstico e atrás do líder nacional, sentam-se figuras partidárias, parlamentares, porta-vozes das agências domésticas, representantes de grupos chave de interesses e os assessores políticos do próprio líder (PUTNAM, 2010, p. 151).
}

Simplificadamente, Putnam (2010, p. 150) esclarece que uma abordagem com relação aos determinantes domésticos da política externa e, levando em consideração tudo aquilo que o autor define como luta política Conforme destaca Carvalho (2010), grupos de interesse doméstico atuam, direta ou indiretamente, como sinalizadores de apoio doméstico ao Executivo em matérias internacionais de seu interesse, permitindo que sejam interpretados como parte do processo de formulação de política externa brasileira.

Assim, compreender a atuação de um determinado grupo de interesse em algum aspecto da política é uma tarefa necessária à compreensão da maneira como a política externa é feita, como sugere Figueira (2011). Dando enfoque ao caso do lobby no Brasil, é preciso levar em consideração dois aspectos. O primeiro deles trata da formação do Estado, surgido de uma base de relações clientelistas, pessoalizadas e informais, tornando as práticas políticas do aparelho estatal pouco transparentes e duvidosas (BAHIA, 2003). O segundo, conforme coloca Ribeiro (2016), está na importância de ressaltar a ausência de uma institucionalidade no lobby 
quanto à sua atuação no Brasil. Como este não é um mecanismo legalizado, como ocorre nos Estados Unidos, o processo carece de maior transparência. Ainda assim, o lobby do agronegócio e o FPA caracterizam-se como Grupos de Interesse no processo decisório da política externa brasileira (PEB).

Boarin e Resende (2018) destacam que a atuação de um determinado grupo de interesse junto ao processo decisório de política externa brasileira conta com instrumentos institucionalizados, permitindo uma interferência ex ante e ex post na produção de política. Instrumentos ex ante se caracterizam pelo poder da agenda e dos instrumentos que permitem a canalização dos interesses dos parlamentares com relação às mensagens da presidência que são enviadas ao Congresso. Silva e Spohr (2016) destacam que a determinação dos princípios da política externa exige uma atuação do MRE dentro de padrões específicos, resultando em um processo de interlocução com o Congresso que torna o processo de produção da política externa permeado pela atuação do Executivo, Legislativo e de grupos de interesse, abrindo espaço para que suas preferências se insiram no processo decisório. Observa-se, neste aspecto, a atuação destes grupos dentro das Comissões Permanentes na Câmara de Deputados. Como elemento ex post, como explicam Boarin e Resende (2018, p. 217), "ao acordar ou discordar das proposições legislativas, o que os constitui em veto players". Ribeiro (2016) destaca, ainda, associação entre os diferentes grupos que representam entidades conectadas ao agronegócio e financiamentos privados, que acabam por nortear as decisões dos parlamentares frente pautas políticas.

A visualização do agronegócio como um lobby, hoje, decorre de três poderes específicos, caracterizados por Jennifer Clapp e Doris Fuchs (2009) como poderes instrumentais, estruturais e discursivos. Em linhas gerais, dizem respeito à capacidade deste grupo de pressionar ou influenciar uma determinada agenda a fim de influenciarem seu resultado, à capacidade de controlar e delimitar o espaço de ação política dos Estados a partir da posição que ocupam na economia a fim de constranger o conteúdo, a construção e a aplicação de mecanismo de governança e à capacidade de construção de discursos capazes de penetrarem fóruns públicos de governança global a fim de buscar adesão a políticas que atendam aos seus respectivos interesses político-financeiros, respectivamente. Essa 
associação entre público e privado, conforme descreve McMichael (2016), provoca uma financeirização da agricultura que subtrai o valor sociocultural dos alimentos, favorecendo a instabilidade de preços e a recorrência de crises alimentares (CLAPP; ISAKSON, 2018).

Sendo o agronegócio um dos principais pilares da economia de diversos países do Sul Global, intensifica-se esse processo de financeirização e cresce o domínio exercido por empresas tanto que vendem máquinas agrícolas e agrotóxicos, quanto que produzem alimentos, provocando uma série de eventos que permite a associação dos interesses dessas corporações transnacionais ao apoio de representantes do agronegócio inseridos na FPA. $O$ lobby é definido por Boarin (2015) como a atividade desempenhada por um grupo de interesse que transmite suas pautas aos tomadores de decisões por meio de representantes especializados. É a defesa de seus interesses, de forma lícita ou ilícita, com estratégias de mobilização que vão desde o contato direto com o tomador de decisão e seus assessores até à obtenção do apoio da opinião pública.

Uma das formas de analisar a instituição desse lobby jaz no Congresso Brasileiro e na formação estrutural que, especificamente, é apresentada pela FPA. Sua estrutura transversal reúne representantes da direita e centro-direita, e alguns representantes da esquerda, contando com cerca de 257 signatários em 2019, dos mais variados partidos, fiéis às pautas que se contrapõem a medidas antiescravagistas, ambientalistas ou reformas agrárias, criminalizando movimentos como o Sem-Terra. Historicamente, a FPA tem uma participação relevante de proprietários de terras em sua composição, apresentando não apenas relações com propriedades ou atividades do agronegócio, mas inclusive aderindo às causas de interesse do agronegócio. Conforme observa-se no site da Câmara de Deputados (2020a), e é apontado por Ribeiro Neto (2018), a participação de pequenos e médios agricultores na FPA é ocasional, já que a composição deriva, em grande medida, de parlamentares anteriormente ligados à União Democrática Ruralista (UDR).

Com relação aos principais interesses da FPA, o documento do Departamento Intersindical de Assessoria Parlamentar (DIAP) referente ao período de 2019-2023, as principais pautas da FPA tratam de "meio ambiente, regulamentação da Emenda Constitucional $81 / 2014$, regulamentação da aquisição de terras por estrangeiros, demarcação 
de terras indígenas e anistia às dívidas de produtores rurais". As pautas de interesse da FPA podem ser observadas na Tabela 1.

Tabela 1 - Eixos temáticos dos interesses da Frente Parlamentar da Agropecuária

\begin{tabular}{|c|c|c|}
\hline Eixo Temático & Interesses & Fontes \\
\hline Meio Ambiente & $\begin{array}{l}\text { PL 3729/2004; modificação do Código Florestal; Política } \\
\text { Nacional de Biocombustíveis (Lei no 13576/2017); } \\
\text { Licenciamento Ambiental (PL 3792/2004) }\end{array}$ & $\begin{array}{l}\text { FPA (2016); Brasil (2017); } \\
\text { Câmara de Deputados } \\
\text { (2019b); Câmara de } \\
\text { Deputados (2019c) }\end{array}$ \\
\hline Política Agrícola & $\begin{array}{l}\text { Crédito Rural; Medida Provisória no } 733 / 2015 \text { (agora Lei no } \\
\qquad 13.340 / 2016) .\end{array}$ & FPA (2016); Brasil (2016) \\
\hline Defesa Sanitária & $\begin{array}{l}\text { Modificação da Lei da Biossegurança (Lei no 11.105/2005); } \\
\text { modificação das Resoluções Normativas 02/2006 e 05/2008; } \\
\text { Liberalização de Agrotóxicos (Ato no 42/2019; Ato no } \\
\text { 62/2019; Ato no36/2020). }\end{array}$ & $\begin{array}{l}\text { Câmara de Deputados } \\
\text { (2002); Câmara de } \\
\text { Deputados (2015); FPA } \\
\text { (2016); }\end{array}$ \\
\hline $\begin{array}{l}\text { Infraestrutura e } \\
\text { Logística }\end{array}$ & $\begin{array}{l}\text { Investimento em hidrovias, por meio dos Projetos de } \\
\text { Decretos Legislativos 118, } 119 \text { e } 120 \text { de } 2015 .\end{array}$ & FPA (2016); Ferreira (2017); \\
\hline
\end{tabular}

Estrangeirização de terras pelo Projeto de Lei no 2289/2007; questões que tratam da reforma agrária, da defesa de terras

Direito de adquiridas, a compra de terras e mais; Projeto de Lei 4059/2012,

FPA (2016);

Propriedade sobre aquisição de áreas rurais por pessoas físicas e jurídicas estrangeiras; Projeto de Lei no 2963/2019 (Terra Para + Empregos e + Lima, Pereira e Barbanti (2018); Alimentos).

\begin{tabular}{|c|c|c|}
\hline $\begin{array}{c}\text { Relações } \\
\text { Internacionais }\end{array}$ & $\begin{array}{l}\text { Protocolo de Nagoya sobre acesso a recursos energéticos e sua } \\
\text { utilização, tramitando por meio da Mensagem de Acordos no } \\
\text { 245/2012; Plataforma para o Biofuturo. }\end{array}$ & $\begin{array}{c}\text { FPA (2016); } \\
\text { Moreira (2016) }\end{array}$ \\
\hline $\begin{array}{l}\text { Agricultura } \\
\text { Familiar }\end{array}$ & $\begin{array}{l}\text { Alguma preocupação para com pequenos agricultores e a agricultura } \\
\text { familiar; extinção da Coordenação-Geral de Cooperação Humanitária } \\
\text { e Combate à Fome (CGFome) do Itamaraty. }\end{array}$ & $\begin{array}{l}\text { FPA (2016); } \\
\text { Papi e } \\
\text { Medeiros } \\
\text { (2017) }\end{array}$ \\
\hline
\end{tabular}

Fonte: Da Autora (2020). 
Cabe ressaltar que a composição da FPA no Congresso Nacional é apenas uma representação política das organizações de apoio que fomentam estes deputados e senadores (SIMIONATTO; COSTA, 2012). Instituições como o Instituto Pensar Agro (IPA), a Confederação Nacional da Agricultura e Pecuária do Brasil (CNA) e organizações setoriais atuam como complementares uns aos outros, reunindo representantes dos setores público e privado, construindo uma "visão triunfalista dos agronegócios" faz parte do aprofundamento de “agroestratégias" (ALMEIDA, 2010, p. 110), termo que o autor utiliza para definir operações coordenadas entre agentes do agronegócio.

Muitas dessas instituições que fomentam o braço político do agronegócio são praticamente invisíveis. Com sites desorganizados e poucas informações disponíveis, prestam suporte técnico à FPA e destinam recursos aos congressistas. Estes recursos são oriundos de 38 associações mantenedoras do IPA, como aponta Arroyo (2019). Ligadas a estas associações, encontram-se grandes companhias do agronegócio brasileiro, cuja relação entre IPA, associações e estas companhias é cultivada por meio de almoços semanais que ocorrem no Lago Sul, bairro nobre de Brasília. Pode-se observar a composição das associações a partir da Tabela 2.

Tabela 2 - Associações financiadoras da FPA e companhias que as compõem

\begin{tabular}{|c|c|}
\hline Associação & Empresas Participantes \\
\hline \multirow{5}{*}{ Associação Brasileira da Proteína Animal (ABPA) } & BRF \\
\hline & Monsanto \\
\hline & Aurora \\
\hline & Seara \\
\hline & $3 \mathrm{M}$ \\
\hline \multirow{3}{*}{ União da Indústria de Cana de Açúcar (Única) } & Bunge \\
\hline & Biosev \\
\hline & São Martinho \\
\hline \multirow{2}{*}{$\begin{array}{l}\text { Associação Brasileira da Indústria do Fumo } \\
\text { (Abifumo) }\end{array}$} & Souza Cruz \\
\hline & Philip Moris \\
\hline
\end{tabular}




\begin{tabular}{|c|c|}
\hline $\begin{array}{l}\text { Associação Brasileira dos Produtores de Sementes } \\
\text { de Soja (Abrass) }\end{array}$ & Amaggi \\
\hline \multirow{6}{*}{$\begin{array}{l}\text { Sindicato Nacional da Indústria de Alimentação } \\
\text { Animal (Sindirações) }\end{array}$} & Yara \\
\hline & BRF \\
\hline & Dupont \\
\hline & JBS \\
\hline & Bayer \\
\hline & BASF \\
\hline \multirow{3}{*}{$\begin{array}{l}\text { Sindicato Nacional da Indústria de Produtos para } \\
\text { Saúde Animal (Sindan) }\end{array}$} & Eurofarma \\
\hline & Cargill \\
\hline & Bayer \\
\hline \multirow{5}{*}{ Associação Brasileira do Agronegócio (Abag) } & Algar \\
\hline & Banco do Brasil \\
\hline & Sicredi \\
\hline & Bayer \\
\hline & Sicredi \\
\hline
\end{tabular}

* São apresentadas aqui apenas algumas das associações que foram observadas.

Fonte: Instituto Pensar Agro e associações e De Olho nos Ruralistas (2019).

A influência destas organizações setoriais e empresariais ajuda a fomentar a pauta política da FPA. A FPA tem histórico de participação política, presente no governo de Lula da Silva, mais fortemente durante o governo de Dilma Rousseff, enquanto a ex-presidenta buscava apoio político para se manter no poder. Foram exímios apoiadores do impeachment e abraçaram o governo de Michel Temer a partir da exposição da "Pauta Positiva da FPA", elaborada pelo IPA e pela FPA para o Biênio 2016/2017 (FPA, 2016). Foram apoiadores da candidatura de Jair Bolsonaro e seguem como base de seu governo. Tais elementos apontam a relação entre agronegócio e governo federal cada vez mais próxima, indicando sua participação efetiva na política brasileira. Essa influência se estende à política externa brasileira justamente porque é um espaço importante para expansão do agronegócio brasileiro. A FPA estende seus domínios ao indicar aliados para ocuparem cargos estratégicos 
em diversos órgãos públicos, como é o caso das superintendências do Incra e da Funai em regiões de expansão do agronegócio. E isso se repete em comissões, relatorias e outros espaços que são considerados estratégicos no Congresso Nacional. (CASTILHO, 2012; CIOCCARI; PERSICHETTI, 2020).

\section{ASSOCIAÇÃO ENTRE AGRONEGÓCIO E POLÍTICA EXTERNA DO BRASIL: A REPERCUSSÃO DO AGROLOBBY NO PROCESSO DECISÓRIO}

Dois fatores foram fundamentais para o desempenho do setor agrícola no Brasil a partir da década de 1980. Primeiramente, a redemocratização política e, consequentemente, a modificação da política econômica desenvolvimentista, iniciada em 1930, com Getúlio Vargas, garantindo a exportação de produtos agrícolas e uma maior mobilidade do setor, após a estabilização monetária adquirida a partir do Plano Real. Combinados, estes dois elementos garantiram maior competitividade ao setor, permitindo a integração doméstica ao processo de globalização (CARPENEDO, 2015) Cabe destacar, ainda, três fatores essenciais às melhorias no desempenho do setor: (1) investimento em pesquisa e desenvolvimento, relacionada ao aumento na produção agrícola e pecuária; (2) a consolidação de mecanismos de financiamento do setor; e (3) a organização do agronegócio com relação ao novo modelo de formulação de PEB $^{3}$ (GUASQUES et al., 2004).

Como explica Figueira (2011), a formulação de PEB até os anos 1990 estava condicionada exclusivamente ao Ministério das Relações Exteriores (MRE), estrutura que adveio da reforma do Estado em 1936. Entretanto, o processo de redemocratização política parece ter aumentado a preocupação, como coloca Carpenedo (2015), com canais de discussão que fossem mais "abertos e transparentes com a sociedade civil, processo que [...]

\footnotetext{
${ }^{3}$ Dentre as características do novo modelo administrativo estavam: a tecnicidade, a profissionalização, a neutralidade política, a centralização, a hierarquização, o caráter meritocrático das carreiras, os critérios gerais e uniformes de classificação de cargos, a racionalização geral dos métodos e ênfase nos procedimentos. Esse segundo ciclo de reformas e ruptura na história da organização das instituições públicas federais teve impacto significativo na organização do Ministério das Relações Exteriores, pois foi durante esse período que a carreira diplomática se tornou unificada, possibilitando a constituição de um grande espírito de corpo. Além disso, conquistou autonomia em relação às demais burocracias estatais na promoção e execução de seu processo seletivo para a inserção na carreira, com a criação da academia diplomática em 1945 (FIGUEIRA, 2011, p. 8).
} 
envolveu o Itamaraty, que também passou a considerar essa interlocução como necessária na constituição de uma política externa". Tem-se, assim, uma pressão com relação a mudanças constitucionais que permitissem um maior equilíbrio entre Executivo e Legislativo no tocante à formulação de $P E B$, um crescente ativismo do Congresso com relação à $P E B$, uma intensificação da diplomacia presidencial, a busca por uma inserção competitiva, ampliação da atuação diplomática e uma erosão, ao longo do governo de Lula da Silva, da coesão do corpo diplomático. Nesse sentido, percebe-se maior abertura e interlocução do Itamaraty com o Legislativo e o empresariado brasileiro, multiplicando o número de atores interessados na formulação de PEB (VIGEVANI, CEPALUNI, 2007; FARIA, 2012; CARPENEDO, 2015).

Isso, somado ao processo de internacionalização do Ministério da Agricultura, Pecuária e Abastecimento (MAPA), a partir da nova pasta proposta em 1992, garantiu canais de diálogos nos quais se valorizava o agronegócio e dava-se maior visibilidade e efetividade às suas políticas públicas. Assim, em 1998, criou-se o Conselho do Agronegócio (CONSAGRO), que reúne representantes dos setores público e privado, bastante semelhante à divisão existente no Comitê de Segurança Alimentar (CSA), pertencente à Food and Agriculture Organization (FAO), denominada de Private Sector Mechanism (PSM), onde ONGs, movimentos campesinos transnacionais e corporações possuem assentos de debate acerca de assuntos referentes ao sistema agroalimentar mundial (SANTOS, 2017). O CONSAGRO trabalha em conjunto com a Confederação da Agricultura e Pecuária do Brasil (CNA) e a Associação Brasileira de Agribusiness ( $A B A G$ ) no fortalecimento da importância do setor agroindustrial junto ao governo, à iniciativa privada e a entidades diversas (ABAG, 2015). Em conjunto, formaram, em 1999, o Fórum Permanente de Negociações Agrícolas Internacionais e o Instituto de Estudos do Comércio e Negociações Internacionais (ICONE).

Para Carvalho (2010), o ICONE tornou-se um interlocutor entre o MAPA e o MRE, como uma forma de exercer influência sobre a formulação de PEB. Entretanto, como explica Ribeiro (2016) ao analisar a proposta analítica de Milner (1997), exercer pressão sobre determinado aspecto da formulação da política se dá conforme as informações às quais determinado grupo tem acesso. Estudos como o de Veiga (2007), Mancini (2008), Oliveira, Onuki e Mancuso (2011) e Oliveira e Milani (2012) apontam, de forma unânime, que o setor privado se configura 
como um grupo de interesse com recursos capazes de provocar interferência no processo decisório de PEB, podendo ser observado a partir das transformações sofridas pelo MAPA, da abertura do MRE, do surgimento de novos atores e de canais de diálogos, especialmente por meio da união com grupos que se associam a setores do governo.

O MAPA tem origem em 1860, a partir da criação da Secretaria de Estado dos Negócios da Agricultura, Comércio e Obras Públicas. Em 1909, passando a fazer parte da estrutura da República apenas em 1930, a Secretaria se torna o Ministério da Agricultura, Indústria e Comércio. Apenas em 2001, a pasta passa a assumir a denominação de Ministério da Agricultura, Pecuária e Abastecimento. A menção às relações internacionais no regimento do Ministério só foi adicionada em 1992 e em 1966, sofre modificações ao passar a englobar atribuições de acompanhamento e implementação de políticas e acordos internacionais. Em 2005, com a reforma administrativa do Ministério, cria-se a Secretaria de Relações Internacionais do Agronegócio, um marco para as negociações internacionais da pasta (CARPENEDO, 2015).

Somado a isso, a mudança comportamental observada no MRE, provocou o surgimento de atores que passaram a competir com o Itamaraty no processo de formulação de PEB (BARROS, 1986), especialmente porque permitiu maior interlocução com o poder Legislativo e o empresariado brasileiro (CARPENEDO, 2015). A ideia da construção de canais de diálogo seria justamente para manter algum tipo de controle sobre a agenda brasileira no exterior, exatamente porque o processo de democratização e abertura econômica tornaram esse procedimento mais complexo e plural, como explica Ribeiro (2016, p. 4), "com o crescimento da participação de outros Ministérios e agências estatais. Em alguns casos, esses atores iniciariam suas próprias agendas de atividades no plano externo". Apesar de o MRE continuar sendo o principal ator no desenvolvimento de política externa, mesmo os trabalhos de Faria (2012) e Carpenedo (2015) já apontavam para o aumento da participação do Congresso na formulação de PEB a partir dos anos 1990.

A participação do Legislativo e de grupos de interesse na formulação de PEB ocorre de diferentes maneiras. Carpenedo (2005) destaca que a produção e informações técnicas por órgãos externos ao MRE podem apontar medidas benéficas ou prejudiciais ao setor, 
orientando decisões. A participação do MAPA e do MRE em fóruns privados, como aqueles organizados pelo ICONE, também auxiliam na consolidação do lobby, uma vez que as informações produzidas pelo ICONE servem a negociações realizadas pelo MRE, orientam decisões e indicam caminhos que acabam aproximando o lobby da PEB. É nesse sentido que Ribeiro (2016) destaca que todas as associações que cercam a FPA não são excludentes, pelo contrário, caracterizam-se como uma frente unida, que atua em conjunto quando os interesses convergem e os resultados podem ser satisfatórios para o setor. Outro ponto importante, que acentua a participação desse lobby na formulação de PEB reside no Decreto no 6.464, de 27 de maio de 2008, que dispõe sobre a atuação de adidos agrícolas em missões diplomáticas. Ele permitiu que representantes desse lobby passassem a fazer parte de missões diplomáticas aos principais parceiros comerciais do país (BRASIL, 2008).

Conforme o próprio Decreto, um adido agrícola "exercerá missão permanente de assessoramento em assuntos agrícola junto às Missões Diplomáticas brasileiras". Até 2016, cada missão era autorizada a ter apenas um adido agrícola em Missões Diplomáticas em Buenos Aires, Bruxelas, Genebra, Moscou, Pequim, Pretória, Tóquio e Washington. Por meio do Decreto $\mathrm{n}^{\circ} 8.749$, de 9 de maio de 2016, passam a ser permitidos até 25 adidos agrícolas por missão (BRASIL, 2008; 2016). Conforme o MAPA, a relação de adidos agrícolas em 2020 pode ser observada na Tabela 3.

Tabela 3 - Relação de adidos agrícolas por embaixada em 2020

\begin{tabular}{lcc}
\hline \multicolumn{1}{c}{ Posto } & País & Adido \\
\hline Pretória & África do Sul & Jesulindo Nery de Souza Junior \\
Riade & Arábia Saudita & Marcel Moreira Pinto \\
Buenos Aires & Argentina & Priscila Rech Moser Pinto \\
Bruxelas & Bélgica - União Europeia & Guilherme Costa \\
Ottawa & Canadá & Bernardo Todeschini \\
Pequim & China & Luciana Pimenta Ambrozecivius \\
& & Jean Carlo Cury Manfredini
\end{tabular}




$\begin{array}{lcc}\begin{array}{l}\text { Bogotá } \\ \text { Seul }\end{array} & \text { Colômbia } & \text { Marcus Vinicius Segurado Coelho } \\ \text { Cairo } & \text { Coreia do Sul } & \text { Gutemberg Barone de Araújo Nojosa } \\ \text { Washington DC } & \text { Egito } & \text { César Simas Teles } \\ \text { Nova Délhi } & \text { Estados Unidos } & \text { Filipe Guerra Lopes Sathler } \\ \text { Jacarta } & \text { Índia } & \text { Dalci de Jesus Bagolin } \\ \text { Tóquio } & \text { Indonésia } & \text { Gustavo Bracale } \\ \text { Rabat } & \text { Japão } & \text { Ricardo Ossamu Maehara } \\ \text { Cidade do México } & \text { Marrocos } & \text { Nilson César Castanheira Guimarães } \\ \text { Moscou } & \text { México } & \text { Bivanilda Almeida Tápias } \\ \text { Bangkok } & \text { Rússia } & \text { Rafael Guimarães Requião } \\ \text { Hanói } & \text { Tailândia } & \text { Maria Eduarda de Serra Machado } \\ \text { Roma } & \text { Vietnã } & \text { Tiago Charão de Oliveira } \\ \text { Lima } & \text { Singapura } & \text { Leonardo Werlang Isolan } \\ \text { Londres } & \text { Peru } & \text { Ângela Pimenta Peres } \\ \text { Singapura } & \text { Leandro dos Santos Antunes }\end{array}$

Fonte: MAPA (2020).

Conforme publicado no Diário da União em dezembro de 2019, os adidos das embaixadas de Riade, Pretória, Buenos Aires, Pequim, Nova Délhi, Seul, Cidade do México, Bangkok e Hanói foram reconduzidos aos cargos (BRASIL, 2019). A ideia da ampliação dos adidos, que ganha força desde 2016, é a promoção de maior diálogo entre a base técnica e política, uma vez que a atuação de um adido está ligada à busca por melhores condições de acesso a produtos do agronegócio e ao estudo de políticas agrícolas e legislações pertinentes ao espaço agrícola do país (BRASIL, 2018; ESTADO DE MINAS, 2020).

Nesse sentido, observando o exposto por Iglécias (2007), é possível perceber a atuação do agronegócio junto ao Estado na formulação de PEB a partir de alguns objetivos específicos, que evidenciam os Jogos de Dois Níveis ao demonstrarem como o interesse de grupos domésticos influência a movimentação do Brasil no cenário internacional. Primeiramente, o lobby atua na geração de investimentos externos, em órgãos como Ciência e Tecnologia, 
logística e infraestrutura que beneficiem a área. Conforme destacam Viela e Araújo (2006) e Carpenedo (2015), a interlocução entre o lobby e os Ministérios decorre da prioridade da organização das demandas, dando visibilidade a políticas públicas voltadas ao agronegócio, com destaque para o CONSAGRO. Trabalhando em conjunto com a CNA e a ABAG, a associação se tornou um articulador de planejamento, identificação e implementação de prioridades na política agrícola e de metas socioeconômicas, auxiliando na produção do Plano Safra e na determinação e diretrizes do setor nos mercados interno e externo. Percebe-se que esse processo permitiu maior investimento no setor agroexportador, como demonstra o Gráfico 1, que aponta a distribuição e recursos de crédito agropecuário de 2011 a 2017, apontando que no ano de $2016,87 \%$ dos recursos se destinaram ao agronegócio.

Gráfico 1 - Distribuição de recursos de crédito agropecuário no período de 2012 a 2017, em bilhões (R\$)

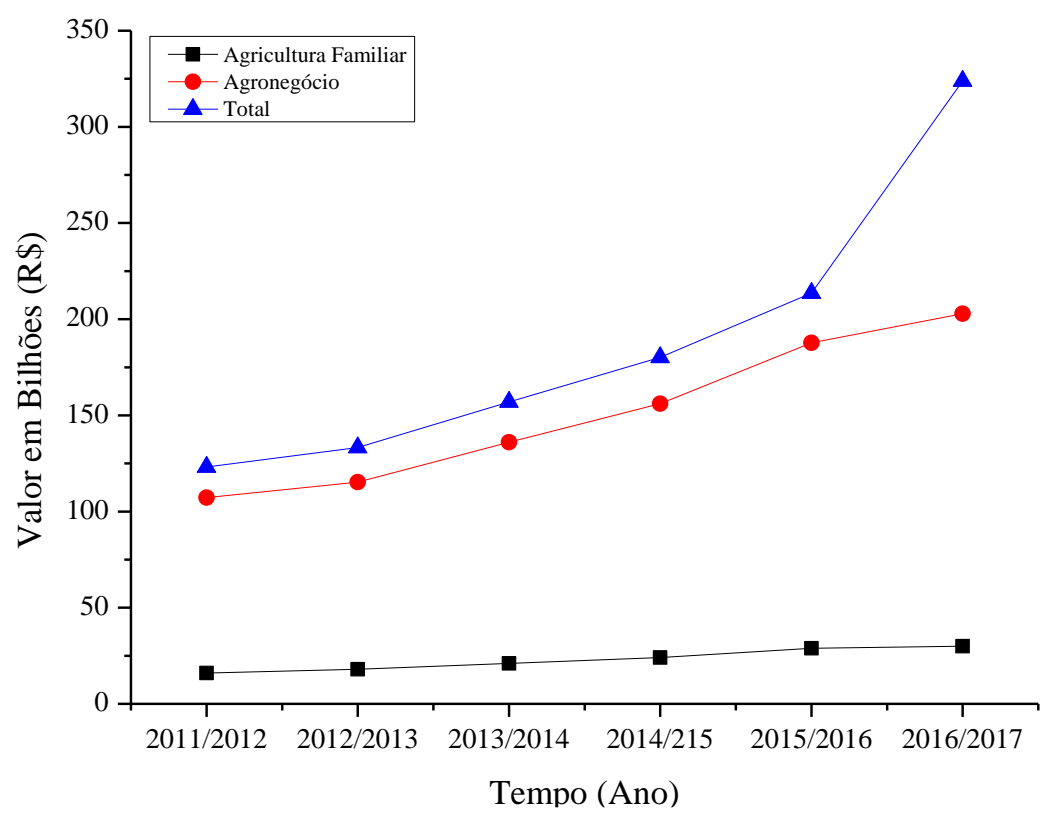

Fonte: Elaborado pela autora (2020), com base nos dados do MAPA (2010; 2011; 2012; 2013; 2014; 2015; 2016) e MDA (2010; 2011; 2012; 2013; 2014; 2015; 2016).

O CONSAGRO atua no fortalecimento do setor agroindustrial junto ao governo e serve como ponte entre o setor público e as diversas entidades da iniciativa privada. Entendendo sua interlocução com o espaço público, pode-se observar um segundo objetivo: a negociação 
de regras sanitárias e leis de certificação. A aproximação da CNA com o governo federal durante o segundo mandato de Rousseff (2014-2016) evidenciou a atuação da agrolobby na busca por espaço de diálogo com parceiros comerciais do Brasil. Em conjunto com o governo, a CNA estabeleceu o Plano Decenal de Cooperação entre Brasil e China, com o propósito de promover o agronegócio e a abertura de mercados para a pesquisa e a formação de parcerias industriais. Esse processo permitiu que a CNA criasse um escritório de promoção do agronegócio em Pequim, que realiza estudos de tendências de consumo e oportunidades de negócio. O escritório entra em contato com os importadores, entendendo demandas e requisitos. As informações são repassadas à Agência Brasileira de Promoção de Exportações e Investimentos (Apex-Brasil) e aos adidos agrícolas em Pequim (MRE, 2013; CNA, 2020).

Com base nisso, a CNA passou a acompanhar ativamente o processo de negociação de regras sanitárias e certificação para que os produtos produzidos pelo agronegócio, possam, de fato, chegar aos seus destinos. Foi o caso do Tratado Internacional sobre Recursos Fitogenéticos para Agricultura e alimentação (TIRFAA), que trata da conservação e do uso de recursos fitogenéticos com base em algumas ações de desenvolvimento, pesquisa, expansão e cultivo sustentável e de estratégias de melhoramento genético (FAO, 2019). A CNA aconselhou que a FPA votasse contra a proposta a menos que houvesse a inclusão dos cultivos de soja, café e cana-de-açúcar. A proposta foi votada na CREDN em 2010, sob a relatoria do Deputado Chico Rodrigues, membro da Bancada Ruralista de 1991 a 2005 e da FPA de 2005 a 2011. A atuação da FPA nesse sentido também leva a um terceiro objetivo citado por Iglécias (2007): a mitigação e a redução de barreiras tarifárias ou protecionistas impostas por outros países.

Uma vez que a CNA cria escritórios internacionais, tem relação próxima com instituições de promoção do comércio e adidos nos mais diversos postos, evidencia-se uma profissionalização do lobby do agronegócio, como citado por Iglécias (2007), devido a vantagens comparativas, como a extensa participação em Comissões Permanentes, e a existência de think tanks focados em sua inserção internacional. A CREDN, uma das 25 Comissões Permanentes da Câmara de Deputados, atua sobre matérias internacionais que se refiram a defesa, direito internacional público, nacionalidade, relações diplomáticas, 
consulares, comerciais, econômicas, culturais e científicas. Para a FPA, a CREDN é um importante espaço de atuação na conquista de seus objetivos externos e representa essa interação da demanda doméstica sobre a atuação externa de um Estado, como Putnam (2010) teorizou. O autor sugere considerar a luta política, fazendo assim, uma ponte com a análise da atuação do agrolloby dentro da CREDN.

Silva e Spohr (2016) e Pereira (2019) destacam que um dos mecanismos de atuação de grupos de interesse no Congresso envolve as Comissões e ajuda a observar a pluralização da política externa. Araújo e Silva (2016) ressaltam, ainda, que não há uma regra que exija que um membro esteja diretamente conectado com as pautas da FPA. Conforme Bachrach e Barazt (2011), essa seria a "face invisível do poder", a capacidade que um determinado grupo de interesse possui de arregimentar apoiadores e de controlar ou manipular valores sociais e políticos. Nesse sentido, Bahia (2003) propõe que a lógica corporativista é um dos elementos que garantem o sucesso dessa inserção do lobby no espaço público. É possível identificar quatro padrões institucionalizados, chamados pelo autor de gramática, por definirem uma linguagem e um modo de agir: clientelismo, corporativismo, insulamento burocrático e universalismo de precedentes.

Na análise de Ribeiro (2016) acerca da proposta de Bahia (2003), foi identificada a coexistência desses quatro padrões, revelando uma atuação deste grupo de interesse de forma recorrente e pouco institucionalizada. Por meio disso, percebem-se novas dinâmicas internacionais que garantem a expansão do processo de governança e que inserem novos grupos em atividades antes muito mais condizentes com a atuação dos Estados. Assim, fica clara a atuação do lobby agronegócio junto à formulação de PEB devido aos recursos, às informações privilegiadas e aos canais de atuação que este dispõe, fazendo uso de estratégias de articulação com outras bancadas, por meio da troca de favores, construção de alianças com grupos não estatais, uma representação partilhada que permite sua atuação em assuntos que vão além do âmbito rural, cooptando, ainda, meios de comunicação e usando discursos que são internalizados pelo público.

No âmbito da CREDN, a evolução da participação do agronegócio em decisões de política externa brasileira se acentua justamente na composição da Comissão. Conforme 
prevê o Regimento Interno da Câmara de Deputados (RICD), o número de membros de cada Comissão Permanente é definido no início de cada Legislatura, a partir do ato da Mesa da Câmara. O número de membros leva em consideração a composição da Câmara diante do número de Comissões e observa o princípio da proporcionalidade partidária (CÂMARA DE DEPUTADOS, 1989). Percebe-se, nesse sentido, um aumento da participação do número de membros da FPA na CREDN, especialmente em 2019. Conforme os relatórios da CREDN, existe uma proporcionalidade de membros até 2018, mas em 2019, o número total de membros foi consideravelmente menor, conforme demonstra a Tabela 4.

Tabela 1 - Componentes do CREDN que fazem parte da FPA

\begin{tabular}{|c|c|c|}
\hline Ano & Componentes no CREDN da FPA & Membros do CREDN \\
\hline 2010 & 7 & 62 \\
\hline 2011 & 20 & 62 \\
\hline 2012 & 11 & 57 \\
\hline 2013 & 14 & 61 \\
\hline 2014 & 14 & 65 \\
\hline 2015 & 19 & 66 \\
\hline 2016 & 17 & 63 \\
\hline 2017 & 22 & 64 \\
\hline 2018 & 18 & 63 \\
\hline 2019 & 19 & 38 \\
\hline
\end{tabular}

Fonte: Elaborado pela autora (2020), com base nos dados da CREDN (2010; 2011; 2012; 2013; 2014; 2015; 2016; 2017; 2018; 2019).

Sugere-se que a mudança no número total membros da Comissão possa se dever a: 1) a mudança na documentação da Comissão, que passou a ser gravada e não possui, no ano de 2019, ainda, um relatório escrito, o que dificultou a avaliação da composição; 2) o próprio site da Comissão não está completo e, dessa forma, não apresenta a composição completa; e 3) o número realmente reduziu, sem uma explicação aparente. Apesar disso, percebe-se o 
entrelaçamento da FPA com a política externa brasileira e, consequentemente, a aproximação do agrolloby com o processo decisório. Fomentada e coordenada pela CNA, IPA e outras entidades, a FPA é o braço político desse lobby para que sua presença sobre questões importantes, que se conectem aos principais temas do setor, seja regular e permita a interlocução com Ministérios como o MAPA e o MRE.

Nesse sentido, a proposta analítica do foreign policy system, ao sugerir um processo de inputs e outputs, cabe bem à análise da interação de grupos de interesse. A FPA se caracteriza como um input devido à força política que possui, as entidades conectadas ao agronegócio - CNA, IPA, ICONE, ABAG, ABRAMILHO... - são parte dessa estrutura, compondo o lobby e servindo como inputs à orientação política da FPA, que reflete as demandas do setor na Câmara. Como outputs, existem as políticas resultantes dessa interação entre lobby e Legislativo e Legislativo e MRE. Nesse caso, destacam-se algumas questões pertinentes ao setor, cujas discussões passam pela CREDN, conforme Carpenedo (2015), Ribeiro (2016) e Lima, Pereira e Barbanti (2018), como a estrangeirização de terras ${ }^{4}$, a Plataforma para o Biofuturo e a alteração da lei de biossegurança, que afetam o setor, interna e externamente.

Como colocam Lima, Pereira e Barbanti (2018), o processo de estrangeirização de terras também é elemento conectado ao agronegócio, principal força desse processo, seja pela possibilidade de parcerias com o capital estrangeiro ou pela capitalização que decorre da venda das propriedades. Para conceituação, a estrangeirização se caracteriza pela territorialização da terra por outros, como explica Pereira (2017). Desde 2012, com a criação do Projeto de Lei $n^{\circ}$ 4.059/2012, já existia uma pressão sobre territórios campesinos, agravando os conflitos no campo. Em 2019, conforme o site da Câmara de Deputados, o Projeto de Lei foi desarquivado (CÂMARA DE DEPUTADOS, 2020).

Em 2017, o governo de Michel Temer elencou a liberalização de regras que restringem o investimento estrangeiro em terras do campo como prioridade, e tinha como entusiasta o então Ministro da Agricultura, Blairo Maggi, um dos maiores produtores mundiais de soja e milho, especialmente ao colocar que tais restrições poderiam se aplicar a culturas não

\footnotetext{
${ }^{4}$ Do inglês land grabbing.
} 
perenes, como soja e milho, por exemplo (CUNHA, 2017; SCARAMUZZU, 2016). Sendo a estrangeirização um debate pertinente à pauta da FPA, o espaço doméstico nos Jogos de Dois Níveis de Putnam (2010) pode ser aqui observado a partir da atuação do lobby em vender uma ideia de desenvolvimento econômico e crescimento da produção. Essa atuação de grupos internos em prol de um movimento transnacional de aquisição de terras, acaba tendo implicações externas, levando-nos às reflexões que Santos (2017) propõe em torno de um regime agroalimentar capitalista, que o aumento da produção pode não ser a resposta às crises alimentares. Castro, Hershaw e Sauer (2017, p. 79) sugerem que o processo de estrangeirização de terras não afeta apenas o campo, "afeta também as relações de trabalho, a internacionalização do capital e a soberania territorial" e alimentar de um país.

Esse processo ganhou ainda mais força ao longo do governo de Jair Bolsonaro, a partir da proposta do Projeto de Lei $n^{\circ}$ 2.963/2019, batizado de "Terra para + Empregos + Alimentos", que sugere a importância de se trazer investimento estrangeiro para o agronegócio como uma garantia de mais empregos e uma maior produção de alimentos, mesmo quando o Censo Agropecuário de 2017 enfatiza o peso da agricultura familiar na alimentação da população brasileira (IBGE, 2017; AGÊNCIA SENADO, 2019; BOMFIM, 2019). O que se observa nesse processo de Estrangeirização de terras é um reforço da financeirização da agricultura, como explicam Castro, Hershaw e Sauer (2017), permitindo a permanência de uma tradição patrimonialista das elites fundiárias, garantindo um conceito privatista da terra, onde se pode fazer o que bem entende com determinado espaço, sem considerar as implicações dessas ações a longo prazo.

O movimento de estrangeirização de terras parece intimamente atrelado ao esvaziamento do "modelo brasileiro", que apesar de problemático5, ainda oferecia pequeno suporte à agricultura familiar, colocando os interesses do agronegócio em larga escala à frente da economia camponesa, agravando a violência no campo, que apresentou um aumento de 12\% no número de conflitos de 2019 para 2020, onde os mais afetados são índios, mulheres

\footnotetext{
${ }^{5}$ Conforme destaca Cunha (2017), a concepção histórica do modelo de desenvolvimento brasileiro acompanha o ideal de desenvolvimento do agronegócio, fundamentado na ocupação territorial e na concentração extensa de propriedades de terra. Onde o espaço rural é visto como "residual e periférico", suporte ao processo de acumulação capitalista na agricultura.
} 
e sem-terra (MADEIRO, 2020; NUZZI, 2020). Paralelamente a isso, retira-se o apoio aos órgãos de segurança alimentar, com menor orçamento a políticas públicas voltadas à agricultura familiar e maior interesse em iniciativas internacionais ligadas ao agronegócio, como foi o caso da Plataforma para o Biofuturo, onde a estratégia brasileira se voltou para o aumento no uso do solo para biocombustíveis e bioenergia derivada de soja e cana-de-açúcar, indo na contramão de outros países que buscavam novas tecnologias que pudessem agregar valor a produtos e processos inovadores (GOMES, 2019; ISMERIM, 2019).

A crítica à proposta se deve a questões como a redução da área de produção e alimentos, considerando que há uma maior produção de culturas não-perenes, que não necessariamente se destinam a alimentar à população. Destaca-se, inclusive, o aumento do desmatamento associado à produção de biocombustíveis, uma vez que: a) desmatar-se-ia floresta para substituir a área de alimentos perdida; ou b) expansão da área de produção para suprir a demanda por produtos agrícolas para produção de biocombustíveis (EMBRAPA, 2014). A iniciativa surge com o apoio Confederação Nacional da Indústria (CNI), da Federação de Indústrias do Estado de São Paulo (FIESP) e de outras representações do setor industrial brasileiro, com uma agenda que carrega uma marca de apoio governamental ao grande agronegócio e aos setores da indústria (LIMA; PEREIRA; BARBANTI, 2018).

Além disso, o apoio observado na alteração da "legislação de acesso ao patrimônio genético e repartição de benefícios, a de biossegurança, de defesa sanitária, de inovação e de propriedade intelectual" (CNI, 2013, pág. 13) acabou por se tornar parte do discurso de defesa para a modificação da Lei 13.123 , de 20 de março de $2015^{6}$. Além disso, a proposta de modificação se estende à lei de Biossegurança, principalmente no que consta às Resoluções

\footnotetext{
${ }^{6}$ Resumidamente, a lei dispõe sobre bens, direitos e obrigações relativos ao acesso ao patrimônio genético do país; ao conhecimento tradicional associado ao patrimônio genético; ao acesso à tecnologia e à transferência de tecnologia para a conservação e a utilização da diversidade biológica; à exploração econômica de produto acabado ou material reprodutivo; à repartição justa e equitativa dos benefícios derivados da exploração econômica de produto acabado ou material reprodutivo oriundo de acesso ao patrimônio genético ou ao conhecimento tradicional associado, para conservação e uso sustentável da biodiversidade; à remessa para o exterior de parte ou do todo de organismos, vivos ou mortos; e à implementação de tratados internacionais sobre o patrimônio genético ou o conhecimento tradicional associado, aprovados pelo Congresso Nacional e promulgados (LIMA; PEREIRA; BARBANTI, 2018).
} 
Normativas 02 de 2006 e 05 de 2008, que tratam da aprovação de organismos geneticamente modificados.

Ainda, o ingresso de Guilherme Costa no Codex Alimentarius, entidade afiliada à FAO e à Organização Mundial da Saúde (OMS), também foi de amplo interesse ao agronegócio brasileiro, especialmente por sua trajetória no MAPA e pela especialidade em procedimentos de inspeção e definição de regulamentos para carnes, laticínios e pescados (MAPA, 2017), enfatizando ainda mais a crescente agenda governamental voltada aos interesses do agronegócio na formulação de políticas brasileiras voltadas ao âmbito externo. Há, ainda, que se considerar o largo amparo do governo ao registro de novos agrotóxicos, como no caso do registro de 277 agrotóxicos pelo Ministério da Agricultura sob o comando de Maggi. Em 2018, foram 450 registros (LIMA; PEREIRA; BARBANTI, 2018; CANCIAN, 2019).

Todos esses elementos, como também colocam Lima, Pereira e Barbanti (2018), provocaram mudanças na política externa brasileira. A voz obtida por movimentos sociais era inegável, como se pode observar a atuação do Conselho Nacional de Segurança Alimentar e Nutricional (CONSEA) e do Ministério do Desenvolvimento Agrário (MDA), no espaço internacional no governo Lula da Silva, e a participação destes grupos no processo de elaboração de políticas de comércio exterior e negociações internacionais foi essencial para a construção de programas de combate à fome, por exemplo. No entanto, a mudança do viés político fez com que o poder do agronegócio se sobrepusesse aos interesses de outras demandas, e suas ações para com a formulação e política externa passaram a ser mais acentuadas e atreladas ao governo, varrendo o espaço da agricultura familiar e da economia camponesa da esfera da política externa, passando a assumir um papel internacional que Lima, Pereira e Barbanti (2018, p. 415) chamam de "mera potência do agronegócio".

É essa lógica corporativista, como evidencia Ribeiro (2016), o principal elemento que explica o sucesso do agronegócio na expansão e uma política externa própria. Basta que se observem as negociações da Rodada Doha da OMC, onde o desempenho brasileiro estava condicionado à pressão de grupos domésticos, "resultado da organização e da mobilização dos grupos de interesse do agronegócio" (CARVALHO, 2010, p. 406). A incorporação dos interesses desses grupos pelos Ministérios tornou o MRE cada vez mais dependente da 
expertise de Ministérios ou de empresas públicas na condução de políticas internacionais, como demonstra Silva (2016).

A “Diplomacia do Agronegócio", termo utilizado pelo próprio relatório do MRE sobre os 18 meses de engajamento na valorização do agro brasileiro, é um projeto político e econômico, que permitiu intensificar "a interação e a coordenação do Itamaraty com grupos da sociedade interessados no agronegócio, em particular o Congresso Nacional e as representações do setor privado" (MRE, 2020, p. 15). Este projeto é sustentado pelo pilar do desenvolvimento sustentável, premissa da Plataforma do Biofuturo, que geraria inovação e atrairia investimento, fazendo necessária a proposta de estrangeirização de terras. A estrangeirização de terras, consequentemente, é parte de um discurso de necessidade de produção alimentar, uma vez que é preciso expandir a produção para que se possa garantir alimentos à toda a população (SANTOS, 2017; GBS, 2018; LIMA; PEREIRA; BARBANTI, 2018).

A burguesia agrária é uma fração do Legislativo que mais ganhou força durante o período de 2010 a 2020, em conjunto com a burguesia industrial, os Evangélicos e a Bancada da Bala (DIAP, 2018; PEREIRA FILHO, 2018; CAPELARI et al., 2020). Seu interesse na política externa está relacionado aos ganhos econômicos e políticos que advém da sua posição nas votações - e, claro, de sua atuação na CREDN. Conforme Capelari et al. (2020), este grupo é caracterizado como "Desenvolvimentistas Tradicionais", cujos interesses relacionam-se a uma visão utilitarista dos recursos ambientais e maior espaço à iniciativa privada. Esse grupo de Desenvolvimentistas Tradicionais, formado por representantes do agronegócio, poderosos complexos produtores de commodities e minerais, ocupam posições de destaque, com expressiva representação militar, evangélica e empresários, compartilhando crenças e interesses e intensificando sua participação no espaço político a partir de 2008 (SOARES et al., 2014).

A atuação da FPA no Legislativo é bastante significativa para o agronegócio, especialmente porque se propõe como um canal de diálogo entre entidades, grupos e organizações e o governo. Os membros da FPA participam das Comissões Permanentes e detém espaço significativo nas Comissões Temporárias e Especiais criadas para analisarem propostas de interesse do agronegócio. A redistribuição das cadeiras no Congresso Nacional 
aponta que o grupo domina $44 \%$ das cadeiras na Câmara e 39,5\% das cadeiras do Senado desde 2019 (CAPELARI et al., 2020). É possível observar que a FPA se articulou estrategicamente ao longo dos últimos seis anos, buscando galgar espaços importantes no governo de modo a garantir que suas pautas fossem atendidas. Percebe-se que, isoladamente, a CREDN é espaço de atuação, que não mede sozinha a influência, mas é importante na avaliação da atuação dos ruralistas no governo.

\section{CONSIDERAÇÕES FINAIS}

Levando em consideração os argumentos aqui apresentados, torna-se possível perceber como a instituição de um lobby do agronegócio carrega tanto atores públicos, como a FPA, quanto atores privados. A atuação do grupo de interesse se dá a partir da sua presença no poder Legislativo, e o setor privado é muito bem representado a partir do Congresso. Apesar da dificuldade de se afirmar qual o peso exato do agronegócio quanto às decisões internacionais, sabe-se que eles possuem uma presença marcante na atuação da CREDN, considerando os canais de diálogo que possuem com o MRE, tanto como um lobby, quanto como base institucional. Compreender que a política externa também é uma "política" é dar lugar ao entendimento de que a PEB sofre influência doméstica e internacional, um Jogo de Dois Níveis baseado em interesses e ganhos. Nesse sentido, a proposta de inputs e outputs fica visível quando se avalia a atuação do braço político e institucionalizado do lobby e os resultados observados em relação às políticas marcadas como prioridades dos governos de Temer e Bolsonaro.

É preciso entender que esse processo não é recente. O espaço político do agronegócio sempre esteve ali, com mais ou menos espaço conforme o governo permitia. Esta análise traz um recorte temporal bastante específico dessa intensificação, e, provavelmente, quanto maior o período de abrangência, mais se poderia perceber como é a articulação desse grupo dentro do espaço político e de que maneira essa influência - como, quando, onde, por que e para quê - ela ocorre. A institucionalização do lobby é parcialmente evidente da atuação da FPA e da sua relação com outras entidades do agronegócio, permitindo observar que o 
agronegócio não é apenas uma área da economia, representando a demanda de um grupo relativamente poderoso no Brasil. A associação do lobby com a FPA decorre, muitas vezes, de associações público-privadas justificadas a partir da ideia de desafogar a máquina pública. Resgatando as ideias propostas por Burch e Lawrence (2009), sugere-se que tais associações são meios para a captação de recursos financeiros, abrindo espaço para que este lobby possa exprimir suas ideias e valores (em assuntos diversos) a representantes públicos do setor.

Assim, o argumento de um peso duplo deste lobby, atuando dentro do sistema e fora dele, acaba se fortalecendo a partir de um aumento da presença da FPA na CREDN e a através das entidades do agronegócio que coordenam interesses a serem defendidos na atuação da FPA no Congresso. Pode-se perceber, assim, que existe uma influência crescente do agronegócio nas decisões da política externa brasileira, especialmente a partir de 2016, com a aproximação entre governo Temer e FPA. O peso duplo advém de exercer poder como um lobby enquanto um grupo de interesse ao passo que também exerce poder como base institucional.

O agronegócio é um grupo de interesse que atua dentro do Estado, fazendo parte do aparelho estatal, e elementos como doações às entidades do agronegócio, presença crescente na CREDN, maior interação com Ministérios e Governo e a priorização de políticas que se enquadram nos eixos temáticos que movem as ações do grupo, reforçam a ideia de que o lobby do agronegócio apresenta cada vez mais influência na política externa brasileira. Essa interação é fomentada por grupos privados a partir de entidades conectadas ao agronegócio, abrindo espaço para a expansão da produção, da aquisição de terras, de maior controle sobre a produção alimentar mundial e maior concentração do sistema agroalimentar, permitindo a financeirização da agricultura e a formação de um regime agroalimentar corporativo que tem raízes no espaço público.

Apesar dos resultados obtidos neste artigo, verificando que existe, de fato influência sobre a PEB decorrente do lobby do agronegócio, são necessários mais estudos que aprofundem o tema, para que essa atuação possa ser mais visível e melhor analisada. 


\section{REFERÊNCIAS}

ADDA, Jacques. A Mundialização da Economia: Génese. Lisboa: Terramar, 1997.

AGÊNCIA SENADO. Comissões aprovam projeto que facilita venda de terras para estrangeiros. SENADO FEDERAL, 2019. Disponível em: <https://www12.senado.leg.br/noticias/materias/2019/12/11/comissoes-aprovam-projetoque-facilita-venda-de-terras-para-estrangeiros>. Acessado em 19 julho 2020.

ALMEIDA, Alfredo W. B. Agroestratégias e desterritorialização: os direitos territoriais e étnicos na mira dos estrategistas dos agronegócios. In: . (Ed.) Capitalismo globalizado e recursos territoriais: fronteiras da acumulação no Brasil contemporâneo. Rio de Janeiro: Lamparina, 2010. p. 101-143.

ARAGÃO, Daniel M.; SANTOS, Tiago M. A governança global do desenvolvimento e a despolitização do land grabbing: "there is no alternative"? Estudos Internacionais, v. 5, n. 2, p. 57-73, 2017.

ARAÚJO, Suely M. V. G. de; SILVA, Rafael S e. Frentes e Bancadas Parlamentares: Uma proposta teórico metodológica e de agenda de pesquisa. In: ENCONTRO NACIONAL DA ABCP: CIÊNCIA POLÍTICA E A POLÍTICA - MEMÓRIA E FUTURO, 10., 2016, Belo Horizonte. Anais [...] Belo Horizonte: PUC-Minas, 2016.

ARROYO, Priscilla. Multinacionais são financiadoras ocultas da Frente Parlamentar da Agropecuária. De Olho nos Ruralistas, 2019. Disponível em: < https://deolhonosruralistas.com.br/2019/05/21/multinacionais-sao-financiadoras-ocultasda-frente-parlamentar-da-agropecuaria/>. Acessado em 09 fevereiro 2021.

ASSOCIAÇÃO BRASILEIRA DE AGRIBUSINESS - ABAG. História, Missão e Visão. 2015. Disponível em: < http://www.abag.com.br/institucional/historiamissaovisao>. Acessado em 17 novembro 2019.

AUDI, Amanda; ESSI, Thallita. Relator do projeto dos agrotóxicos é dono de empresas do setor. Congresso em Foco, 2018. Disponível em: < https://congressoemfoco.uol.com.br/legislativo/relator-do-projeto-dos-agrotoxicos-e-donode-empresas-do-setor/>. Acessado em 19 janeiro 2021.

BACHRACH, Peter; BARATZ, Morton S. Duas faces do poder. Revista de Sociologia e Política, Curitiba, v. 19, n. 40, p. 149-157, 2011.

BAHIA, Luiz H. N. O poder do clientelismo: raízes e fundamentos da troca política. Rio de Janeiro: Renovar, 2003. 
BARROS, Alexandre S. C. A Formulação e a Implementação da Política Externa Brasileira: O Itamaraty e os Novos Atores. In: MUÑOZ, H.; TULCHIN, J. S. A América Latina e a política mundial. São Paulo: Convívio, 1986.

BENKO, Georges. Mundialização da Economia, Metropolização do Mundo. Revista do Departamento de Geografia, v. 15, p. 45-54, 2002.

BERNE DECLARATION; ECONEXUS. Agropoly: a handful of corporations control world food production. Zürich: DB \& Econexus, 2013.

BERNSTEIN, Henry. Agrarian political economy and modern world capitalism: the contributions of food regime analysis. The Journal of Peasant Studies, v. 43, n. 3, p. 611-647, 2016.

BJORKHAUG, Hilde; MAGNAN, André; LAWRENCE, G. (Eds.) The financialization of Agri-Foo Systems: Contested Transformation. London: Routledge, 2020.

BOARIN, Paula V.; RESENDE, Ciro. Lobby e Política Externa no Legislativo Brasileiro: a Comissão de Relações Exteriores e Defesa Nacional da Câmara de Deputados. Revista Eletrônica de Ciências Sociais, Juiz de Fora, n. 27, p. 210-240, 2018.

BOMFIM, Ricardo. Venda de terras a estrangeiros será aprovada este ano, avalia senador Irajá Abreu. Infomoney, 2019. Disponível em:

<https://www.infomoney.com.br/mercados/venda-de-terras-a-estrangeiros-sera-aprovadaeste-ano-avalia-senador-iraja-abreu/>. Acessado em 19 julho 2020.

BRASIL. Decreto $n^{\circ} 6.464$, de 27 de maio de 2008. Dispõe sobre a designação e atuação de adidos agrícolas junto a missões diplomáticas brasileiras no exterior, e dá outras providências. Brasília: Diário Oficial da União, 2008.

BRASIL. Decreto $n^{\circ} 8.749$, de 9 de maio de 2016. Altera o Decreto no 6.464, de 27 de maio de 2008, que dispõe sobre a designação e atuação de adidos agrícolas junto a missões diplomáticas brasileiras no exterior. Brasília: Diário Oficial da União, 2016.

BRASIL. Decreto $n^{\circ}$ 9.476, de 20 de agosto de 2018. Altera o Decreto no 6.464, de 27 de maio de 2008, que dispõe sobre a designação e atuação de adidos agrícolas junto a missões diplomáticas brasileiras no exterior, e o Decreto no 99.525, de 14 de setembro de 1990, que institui, no Ministério das Relações Exteriores, o Programa Complementar de Assistência Médica do Serviço Exterior nos casos que menciona. Brasília: Diário Oficial da União, Seção 1, p. 1, 2018.

BRASIL. Decreto no 6.464, de 27 de maio de 2008. Dispõe sobre a designação e atuação de adidos agrícolas junto a missões diplomáticas brasileiras no exterior, e dá outras providências. Brasília: Subchefia para Assuntos Jurídicos, 2009. 
BRASIL. Decretos de 26 de dezembro de 2019. Dispõe sobre a designação e atuação de adidos agrícolas junto a missões diplomáticas brasileiras no exterior, e dá outras providências. Brasília: Diário Oficial da União. Seção 2, p. 10.

BURCH, David; LAWRENCE, Geoffrey. Towards a third food regime: Behind the transformation. Agriculture and Human Values, v. 26, p. 267-279, 2009.

CÂMARA DE DEPUTADOS. PL 4059/2012. 2020. Disponível em: < https://www.camara.leg.br/proposicoesWeb/fichadetramitacao?idProposicao=548018>. Acessado em 19 julho 2020.

CÂMARA DE DEPUTADOS. Resolução no 17/1989, de 21 de setembro de 1989. Aprova o Regimento Interno da Câmara dos Deputados. Câmara de Deputados: Presidência da República, 1989. Disponível em: <https://www2.camara.leg.br/atividadelegislativa/legislacao/regimento-interno-da-camara-dos-deputados>. Acessado em 16 novembro. 2020.

CANCIAN, Natália. Registro de agrotóxicos no Brasil cresce e atinge maior marca em 2018. Folha de São Paulo, 2019. Disponível em: < https://www1.folha.uol.com.br/mercado/2019/03/registro-de-agrotoxicos-no-brasil-crescee-atinge-maior-marca-em-2018.shtml>. Acesso em: 19 jul. 2020.

CAPELARI, Mauro G. M.; ARAÚJO, Suely M. V. G. de; CALMON, Paulo C. du P.; BORINELLI, Benilson. Mudança de larga escala na política ambiental: análise da realidade brasileira. Revista de Administração Pública, Rio de Janeiro, v. 54, n. 6, p. 1691-1710, 2020.

CARNEIRO, Maria J. Agricultores familiares e pluriatividade: tipologias políticas. In: COSTA, L.F.C.; MOREIRA, R.J.; BRUNO, R. (Orgs.). Mundo rural e tempo presente. Rio de Janeiro: Mauad, 1999. p. 323-344.

CARPENEDO, Cássia C. C. C. F. O agronegócio como fator de influência na política externa brasileira: a disputa do algodão entre Brasil e Estados Unidos (2002-2004). Monografia de Graduação de Relações Internacionais, Universidade Federal de Santa Maria, 2015.

CARVALHO, Maria I. V. Condicionantes internacionais e domésticos: o Brasil e o G-20 nas negociações agrícolas da Rodada Doha. Revista de Ciências Sociais, v. 53, n. 2, p. 405-445, 2010.

CASTILHO, Alceu L. Partido da terra: como os políticos conquistam o território brasileiro. São Paulo: Editora Contexto, 2012.

CASTRO, Celso A. P.; FALCÃO, Leonor P. Ciência Política: Uma Introdução. São Paulo: Atlas, 2004. 
CHALOULT, Yves; BRUNELLE, Dorval. Transnacionalização das práticas sindicais: um quadro teórico-analítico. Revista Brasileira de Política Internacional, v. 41, n. 2, 1998.

CIOCCARI, Deysi; PERSICHETTI, Simonetta. O Brasil agrário: o conservadorismo e a direita na bancada ruralista. Em Tese, Florianópolis, v. 17, n. 1, p. 7-32, 2020.

CLAPP, Jennifer. Finanialization, distance and global food politics. The Journal of Peasant Studies, v. 41, n. 5, p. 1-18, 2014.

CLAPP, Jennifer; FUCHS, Doris. Agrifood corporations, Global Governance, and Sustainability: a framework for analysis. In (org.). Corporate Power in Global Agrifood Governance. London: The MIT Press, 2009, p.1-25.

CLAPP, Jennifer; ISAKSON, S. Ryan. Risky Returns: The Implications of Financialization in the Food System. Development and Change, v. 49, n. 2, p. 437-460, 2018.

CLARKE, Michael. The Foreign Policy System: A Framework for Analysis. In: CLARKE, Michael; WHITE, Brian. Understanding Foreign Policy: The Foreign Policy Systems Approach.

Cheltenham: Edward Elgar, 2000.

COCA, Estevan L. de F. a América Latina e o Regime Agroalimentar Corporativo. In:

ENCUENTRO DE GEÓGRAFOS DE AMERICA LATINA (EGAL), 17., 2019, Quito. Anais... Quito, 2019.

COMISSÃO DE RELAÇÕES EXTERIORES E DEFESA NACIONAL DA CÂMARA DE DEPUTADOS CREDN. Relatório de Atividades 2010. Brasília: CREDN, 2010.

COMISSÃO DE RELAÇÕES EXTERIORES E DEFESA NACIONAL DA CÂMARA DE DEPUTADOS CREDN. Relatório de Atividades 2011. Brasília: CREDN, 2011.

COMISSÃO DE RELAÇÕES EXTERIORES E DEFESA NACIONAL DA CÂMARA DE DEPUTADOS CREDN. Relatório de Atividades 2012. Brasília: CREDN, 2012.

COMISSÃO DE RELAÇÕES EXTERIORES E DEFESA NACIONAL DA CÂMARA DE DEPUTADOS CREDN. Relatório de Atividades 2013. Brasília: CREDN, 2013.

COMISSÃO DE RELAÇÕES EXTERIORES E DEFESA NACIONAL DA CÂMARA DE DEPUTADOS CREDN. Relatório de Atividades 2014. Brasília: CREDN, 2014.

COMISSÃO DE RELAÇÕES EXTERIORES E DEFESA NACIONAL DA CÂMARA DE DEPUTADOS CREDN. Relatório de Atividades 2015. Brasília: CREDN, 2015.

COMISSÃO DE RELAÇÕES EXTERIORES E DEFESA NACIONAL DA CÂMARA DE DEPUTADOS CREDN. Relatório de Atividades 2016. Brasília: CREDN, 2016. 
COMISSÃO DE RELAÇÕES EXTERIORES E DEFESA NACIONAL DA CÂMARA DE DEPUTADOS CREDN. Relatório de Atividades 2017. Brasília: CREDN, 2017.

COMISSÃO DE RELAÇÕES EXTERIORES E DEFESA NACIONAL DA CÂMARA DE DEPUTADOS CREDN. Relatório de Atividades 2018. Brasília: CREDN, 2018.

CONFEDERAÇÃO NACIONAL DA AGRICULTURA E PECUÁRIA BRASILEIRA. CNA debate oportunidades para o agro na China. 2020. Disponível em: < https://www.cnabrasil.org.br/noticias/cna-debate-oportunidades-para-o-agro-na-china >. Acessado em 11 fevereiro 2021.

CONFEDERAÇÃO NACIONAL DA INDÚSTRIA - CNI. Bioeconomia, uma Agenda para o Brasil. São Paulo: CNI, 2013.

CUNHA, Andrews R. B. de. A. "PARA NÃO DEIXAR MORRER A AGRICULTURA [FAMILIAR]": projetos, estratégias e práticas de uma história de resistência no semiárido pernambucano. Tese de Doutorado em Sociologia, Universidade Federal de Pernambuco, 2017.

CUNHA, Joaci de S. Governo Temer: Relações do agronegócio com o capital especulativo financeiro e impactos sobre os camponeses e a legislação agrária. Caderno CEAS: Revista crítica de humanidades, n. 241, p. 301-326, 2017.

DEPARTAMENTO INTERSINDICAL DE ASSESSORIA PARLAMENTAR - DIAP. Radiografia do Novo Congresso. Brasília: DIAP. 2018 Disponível em:

https://www.diap.org.br/index.php/publicacoes/category/13-radiografia-do-novocongresso. Acessado em 07 outubro 2020.

EMPRESA BRASILEIRA DE PESQUISA AGROPECUÁRIA - EMBRAPA. O impacto do uso da terra na sustentabilidade dos biocombustíveis. Londrina: Embrapa Soja, 2014.

EPSTEIN, Gerald A. Introduction: the financialization of the world economy. In: EPSTEIN, G. A. (Ed.). Financialization and the World Economy. Elgar: Cheltenham, 2005. p. 1-16.

ESTADÃO DE MINAS. Agronegócio invade diplomacia e faz Brasil formar time de adidos agrícolas. 2020. Disponível em: < https://www.em.com.br/app/noticia/internacional/2020/01/19/interna_internacional,1115 391/agronegocio-invade-diplomacia-e-faz-brasil-formar-time-de-adidos-agric.shtml >. Acessado em 19 julho 2020.

FARIA, Carlos A. P. O Itamaraty e a política externa brasileira: do insulamento à busca de coordenação dos atores governamentais e de cooperação com os agentes societários. Contexto Internacional, v. 34, n. 1, p. 311-355, 2012.

FIGUEIRA, Ariane R. Introdução à análise de política externa. São Paulo: Saraiva, 2011. vol. 1. 
FÓRUM 21; FUNDAÇÃO FRIEDRICH EBERT; GT DE MACRO DA SOCIEDADE BRASILEIRA DE ECONOMÍA POLÍTICA; PLATAFORMA DE POLÍTICA SOCIAL. Austeridade e Retrocesso: finanças públicas e política fiscal do Brasil: São Paulo: FES, 2016.

FRIEDMAN, Harriet. International regimes of food and agriculture since 1870. Peasants and peasant societies, p. 258-276, 1987.

FRIEDMANN, Harriet. Commentary: Food regime analysis and agrarian questions: widening the conversation. The Journal of Peasant Studies, v. 43, n. 3, p. 671-692, 2016.

GASQUES, J. G.; REZENDE, G. C.; VERDE, C. M. V.; SALERMO, M. S.; CONCEIÇÃO, J. C. P. R.; CARVALHO, J. C. S. Desempenho e crescimento do agronegócio no Brasil. Brasília: Ipea, 2004.

GLOBAL BIOECONOMY SUMMIT - GBS. Scaling-up the low carbon bioeconomy: an urgent and vital challenge. 2018. Disponível em:

https://gbs2018.com/fileadmin/gbs2018/Downloads/Biofuture-Platform-Vision-StatementFinal_1_.pdf. Acessado em 14 dezembro 2020.

GOMES, Rodrigo. Governo Bolsonaro suspende financiamento para agricultura familiar. Rede Brasil Atual, 2019. Disponível em: <

https://www.redebrasilatual.com.br/economia/2019/05/governo-bolsonaro-suspendefinanciamento-para-agricultura-familiar/>. Acessado em 19 julho 2020.

GORENDER, Jacob. Globalização, tecnologia e relações de trabalho. Estudos Avançados, v. 11, n. 29, p. 310-361, 1997.

GUASQUES, José G.; REZENDE, Gervásio. C. de; VILLA VERDE, Carlos M.; SALERNO, Mário S.; CONCEIÇÃO, Júnia C. P. R. da; CARVALHO, João C. de S. Desempenho e Crescimento do Agronegócio no Brasil. Brasília: IPEA, 2004.

HIRST, Paul; THOMPSON, Grahame. Globalização em questão. Petrópolis: Editora Vozes, 1998.

IANNI, Octavio. 1997. A política mudou de lugar. In: DOWBOR, L.; IANNI, O.; RESENDE, P. E. (orgs.). Desafios da globalização. Petrópolis, Ed. Vozes, p. 17-27.

IGLÉCIAS, Wagner. O empresariado do agronegócio no Brasil: ação coletiva e formas de atuação política - as batalhas do açúcar e do algodão na OMC. Revista de Sociologia Política, n. 28, p. 75-97, 2007.

INSTITUTO BRASILEIRO DE GEOGRAFIA E ESTATÍSTICA - IBGE. Censo Agropecuário 2017 Resultados Definitivos. Brasília: IBGE, 2017 Disponível em:

<https://sidra.ibge.gov.br/pesquisa/censo-agropecuario/censo-agropecuario-2017>.

Acessado em 06 janeiro 2021. 
INSTITUTO BRASILEIRO DE GEOGRAFIA E ESTATÍ́sTICA. Censo Agropecuário. Rio de Janeiro: IBGE, 2006.

ISMERIM, Flávio. O Início da Batalha. Revista Veja, 2019. Disponível em: < https://veja.abril.com.br/economia/o-inicio-da-batalha/>. Acessado em 19 julho 2020.

KNEEN, Brewster. From land to mouth: Understanding the food system. Toronto: NC Press, 1995.

KRASNER, Stephen D. Structural causes and regime consequences: regimes as intervening variables. International Organization, v. 36, n. 02, p. 185-205, 1982.

MADEIRO, Carlos. Conflito no campo em 2019 foi o maior em 14 anos; luta por água foi recorde. Uol Notícias, 2020. Disponível em: <https://noticias.uol.com.br/cotidiano/ultimasnoticias/2020/04/17/mortes-e-conflitos-no-campo-crescem-em-2019-disputa-por-aguabate-recorde.htm>. Acessado em 19 julho 2020.

MANCINI, Claudia. O agronegócio e as negociações comerciais internacionais: uma análise da ação coletiva do setor privado. Dissertação de Mestrado em Ciência Política, Universidade de São Paulo, 2008.

MCKEON, Nora. The United Nations and Civil Society: legitimating global governance - whose voice? London: Zed Books, 2009.

MCMICHAEL, Phillip. Historicizing food sovereignty. The Journal of Peasant Studies, v. 41, n. 6, p. 933-957, 2013.

MCMICHALE, Phillip. Regimes alimentares e Questões Agrárias. São Paulo:EdUNESP, 2016,

MENDONÇA, Maria L. R. F. de. Modo Capitalista de Produção e Agricultura: A construção do conceito de Agronegócio. Tese de Doutorado em Geografia Humana, Universidade de São Paulo, 2013.

MESQUITA, Lucas R. A formação do Sistema Brasileiro de Política Exterior. Mural Internacional, v. 5, n. 1, p. 71-81, 2014.

MILNER, Hellen V. Interests, Institutions, and Information: Domestic Politics and International. Relations, Princeton University Press, 1997, pp.3-29.

MINISTÉRIO DA AGRICULTURA, PECUÁRIA E ABASTECIMENTO - MAPA. Brasileiro, servidor do Mapa foi eleito presidente do Codex Alimentarius. 2017. Disponível em: < https://www.gov.br/agricultura/pt-br/assuntos/noticias/brasileiro-servidor-do-mapa-foieleito-presidente-do-codex-alimentarius>. Acessado em 19 julho 2020. 
MINISTÉRIO DA AGRICULTURA, PECUÁRIA E ABASTECIMENTO - MAPA. Novos adidos agrícolas assumem missão no exterior. 2020. Disponível em: < https://www.gov.br/agricultura/pt-br/assuntos/noticias/adidos-2020 >. Acessado em 18 julho 2020.

MINISTÉRIO DA AGRICULTURA, PECUÁRIA E ABASTECIMENTO - MAPA. Plano Agrícola e Pecuário 2010-2011. Brasília: MAPA, 2010.

MINISTÉRIO DA AGRICULTURA, PECUÁRIA E ABASTECIMENTO - MAPA. Plano Agrícola e Pecuário 2011-2012. Brasília: MAPA, 2011.

MINISTÉRIO DA AGRICULTURA, PECUÁRIA E ABASTECIMENTO - MAPA. Plano Agrícola e Pecuário 2012-2013. Brasília: MAPA, 2012.

MINISTÉRIO DA AGRICULTURA, PECUÁRIA E ABASTECIMENTO - MAPA. Plano Agrícola e Pecuário 2013-2014. Brasília: MAPA, 2013.

MINISTÉRIO DA AGRICULTURA, PECUÁRIA E ABASTECIMENTO - MAPA. Plano Agrícola e Pecuário 2014-2015. Brasília: MAPA, 2014.

MINISTÉRIO DA AGRICULTURA, PECUÁRIA E ABASTECIMENTO - MAPA. Plano Agrícola e Pecuário 2015-2016. Brasília: MAPA, 2015.

MINISTÉRIO DA AGRICULTURA, PECUÁRIA E ABASTECIMENTO - MAPA. Plano Agrícola e Pecuário 2016-2017. Brasília: MAPA, 2016.

MINISTÉRIO DAS RELAÇÕES EXTERIORES - MRE. Diplomacia do Agronegócio: 18 meses de trabalho. 2020. Disponível em:

<http://www.itamaraty.gov.br/images/Dpagro/Dpagro_18meses.pdf>. Acessado em 15 dezembro 2020

MINISTÉRIO DO DESENVOLVIMENTO AGRÁRIO - MDA. Plano safra da agricultura familiar 2010/2011. Brasília, 2010.

MINISTÉRIO DO DESENVOLVIMENTO AGRÁRIO - MDA. Plano safra da agricultura familiar 2011/2012. Brasília, 2011.

MINISTÉRIO DO DESENVOLVIMENTO AGRÁRIO - MDA. Plano safra da agricultura familiar 2012/2013. Brasília, 2012.

MINISTÉRIO DO DESENVOLVIMENTO AGRÁRIO - MDA. Plano safra da agricultura familiar 2013/2014. Brasília, 2013.

MINISTÉRIO DO DESENVOLVIMENTO AGRÁRIO - MDA. Plano safra da agricultura familiar 2014/2015. Brasília, 2014. 
MINISTÉRIO DO DESENVOLVIMENTO AGRÁRIO - MDA. Plano safra da agricultura familiar 2015/2016. Brasília, 2015.

MINISTÉRIO DO DESENVOLVIMENTO AGRÁRIO - MDA. Plano safra da agricultura familiar 2016/2017. Brasília, 2016.

NUZZI, Vitor. Violência cresce no campo em 2019, com cinco conflitos por dia e 32 assassinatos. Rede Brasil Atual, 2020. Disponível em: < https://www.redebrasilatual.com.br/cidadania/2020/04/violencia-cresce-no-campo-em2019-com-um-conflito-a-cada-cinco-dias-e-32-assassinatos/>. Acessado em 19 julho 2020.

OLIVEIRA, Amâncio J.; ONUKI, Janina; MANCUSO, Wagner P. Política comercial, instituições e Grupos de Interesses. BIB, n. 72, p. 41-54, 2011.

OLIVEIRA, Ivan T. M.; MILANI, Carlos R. S. Atores não estatais e trade policy-making no Brasil: análise dos interesses e das estratégias da CEB e da REBRIP. Dados, v. 55, n. 2, 2012.

PEREIRA FILHO, Osvaldo A. O Bloco no Poder nos Governos Dilma Rousseff (2011-2016): crise e influências na política externa. 2018. Dissertação de Mestrado em Estudos Estratégicos Internacionais, Universidade Federal do Rio Grande do Sul, Porto Alegre, 2018.

PEREIRA, Lorena I. Estrangeirização da terra: (des) construindo uma definição a partir da Geografia. Revista NERA, Presidente Prudente, v. 20, n. 36, p. 107-132, 2017.

PUTNAM, Robert D. Diplomacia e política doméstica: a lógica dos jogos de dois níveis. Revista de Sociologia Política, v. 18, n. 36, p. 147-174, 2010.

RAMBO, José R.; TARSITANO, Maria A. A.; LAFORGA, Gilmar. Agricultura familiar no Brasil, conceito em construção: trajetória de lutas, história pujante. Revista de Ciências Agroambientais, v. 14, n. 1, p. 86-96, 2016.

RIBEIRO NETO, Caio P. Formação Política do Agronegócio. 2018. Tese (Doutorado em Antropologia Social) - Universidade Estadual de Campinas, Campinas, 2018.

RIBEIRO, Renata A. Congresso e Agronegócio na Política Externa Brasileira: dois pesos, duas medidas? In: ENCONTRO DA ASSOCIAÇÃO BRASILEIRA DE CIÊNCIA POLÍTICA. 10., 2016, Belo Horizonte. Anais... Belo Horizonte: Sede da ABCP, 2016. p. 1-24.

SALOMÓN, Mónica; PINHEIRO, Letícia. Análise de Política Externa e Política Externa Brasileira: trajetória, desafios e possibilidades de um campo de estudos. Revista Brasileira de Política Internacional, v. 56, n. 1, p. 40-59, 2013.

SANTARELLI, Mariana; BURITY, Valéria. Da democratização ao golpe: avanços e retrocessos na garantia do direito humano à alimentação e à nutrição adequadas no Brasil. Brasília: FIAN Brasil, 2017. 
SANTOS, Tiago M. "Tendências e Contradições da Influência Corporativa na Agenda Agroalimentar das Nações Unidas". Monções: Revista de Relações Internacionais da UFGD, Dourados, v. 7, n. 13, 2017.

SAUER, Sergio. Agricultura familiar versus agronegócio: a dinâmica sociopolítica do campo brasileiro. Brasília: EMBRAPA, 2008.

SCARAMUZZO, Mônica. Governo Temer discute venda de terras para estrangeiros. Exame Online. 2016. Disponível em: <https://exame.com/brasil/governo-temer-discute-venda-deterras-para-estrangeiros/ >. Acessado em 19 julho 2020.

SILVA, André L. R. da; SPOHR, Alexandre P. A relação entre executivo e legislativo na formulação de política externa no Brasil. Relações Internacionais (Lisboa), v. s/v, p. 123-140, 2016.

SILVA, Ricardo D. da. O papel das coalizões de defesa da agricultura nas agendas da política comercial externa brasileira. Encuentro Latinoamericano, v. 3, n. 1, p. 82-97, 2016.

SIMIONATTO, Ivete; COSTA, Carolina R. Como os dominantes dominam: o caso da Bancada Ruralista. Temporalis, v. 2, n. 24, p. 215-237, 2012.

SOARES, Britaldo; RAJÃO FILHO, Raoni; MACEDO, Marcia; CARNEIRO, Arnaldo; COSTA, William; COE, Michael; RODRIGUES, Hermann; ALENCAR, Ane. Cracking Brazil's forest code. Science, v. 344, n. 6182, p. 363-364, 2014.

TYGEL, Alan. Imperatriz acerta em cheio o umbigo do agronegócio. Brasil de Fato, 2017. Disponível em: <https://www.brasildefato.com.br/2017/01/12/imperatriz-acerta-em-cheioumbigo-do-agronegocio/ >. Acessado em 24 julho 2019.

VEIGA, Pedro M. Política Comercial no Brasil: Características, Condicionantes Domésticos e Policy-Making. In: JANKE, M. S.; SILBER, S. D. (Orgs.), Políticas Comerciais Comparadas: Desempenho e Modelos Organizacionais. São Paulo, singular, 2007. p. 71-162

VIGEVANI, Tullo; CEPALUNI, Gabriel A política externa de Lula da Silva: a estratégia da autonomia pela diversificação. Contexto Internacional, v. 29, n. 2, p. 273- 335, 2007. 